\title{
Longitudinal, population-based study of racial/ethnic differences in colorectal cancer survival: impact of neighborhood socioeconomic status, treatment and comorbidity
} Scarlett Lin Gomez*1,2, Cynthia D O'Malley ${ }^{1}$ Antoinette Stroup ${ }^{3}$, Sarah J Shema ${ }^{1}$ and William A Satariano ${ }^{4}$

Address: ${ }^{1}$ Northern California Cancer Center, Fremont, California, USA, ${ }^{2}$ Health Research and Policy, Stanford University School of Medicine, Stanford, California, USA, ${ }^{3}$ Utah Cancer Registry, University of Utah, Salt Lake City, Utah, USA and ${ }^{4}$ Division of Epidemiology, School of Public Health, University of California, Berkeley, California, USA

Email: Scarlett Lin Gomez* - scarlett@nccc.org; Cynthia D O'Malley - cynthiaomalley@gmail.com;

Antoinette Stroup - nan.stroup@hsc.utah.edu; Sarah J Shema - sshema@nccc.org; William A Satariano - bills@uclink.berkeley.edu

* Corresponding author

Published: 16 October 2007

BMC Cancer 2007, 7:193 doi:10.1186/1471-2407-7-193
Received: 25 April 2007

Accepted: 16 October 2007

This article is available from: http://www.biomedcentral.com//47/-2407/7//93

(c) 2007 Gomez et al; licensee BioMed Central Ltd.

This is an Open Access article distributed under the terms of the Creative Commons Attribution License (http://creativecommons.org/licenses/by/2.0), which permits unrestricted use, distribution, and reproduction in any medium, provided the original work is properly cited.

\begin{abstract}
Background: Colorectal cancer, if detected early, has greater than $90 \%$ 5-year survival. However, survival has been shown to vary across racial/ethnic groups in the United States, despite the availability of early detection methods.

Methods: This study evaluated the joint effects of sociodemographic factors, tumor characteristics, census-based socioeconomic status (SES), treatment, and comorbidities on survival after colorectal cancer among and within racial/ethnic groups, using the SEER-Medicare database for patients diagnosed in 1992-1996, and followed through 1999.

Results: Unadjusted colorectal cancer-specific mortality rates were higher among Blacks and Hispanic males than whites (relative rates $(95 \%$ confidence intervals) $=1.34(1.26-1.42)$ and I.16 (I.04-I.29), respectively), and lower among Japanese $(0.78(0.70-0.88))$. These patterns were evident for all-cause mortality, although the magnitude of the disparity was larger for colorectal cancer mortality. Adjustment for stage accounted for the higher rate among Hispanic males and most of the lower rate among Japanese. Among Blacks, stage and SES accounted for about half of the higher rate relative to Whites, and within stage III colon and stages II/III rectal cancer, SES completely accounted for the small differentials in survival between Blacks and Whites. Comorbidity did not appear to explain the Black-White differentials in colorectal-specific nor all-cause mortality, beyond stage, and treatment (surgery, radiation, chemotherapy) explained a very small proportion of the Black-White difference. The fully-adjusted relative mortality rates comparing Blacks to Whites was I.14 (I.09-1.20) for all-cause mortality and I.2I (I.14-1.29) for colorectal cancer specific mortality. The sociodemographic, tumor, and treatment characteristics also had different impacts on mortality within racial/ethnic groups.

Conclusion: In this comprehensive analysis, race/ethnic-specific models revealed differential effects of covariates on survival after colorectal cancer within each group, suggesting that different strategies may be necessary to improve survival in each group. Among Blacks, half of the differential in survival after colorectal cancer was primarily attributable to stage and SES, but differences in survival between Blacks and Whites remain unexplained with the data available in this comprehensive, population-based, analysis.
\end{abstract}




\section{Background}

Cancers of the colon and rectum are the second leading cause of cancer deaths among men and women in the United States (US), responsible for more than 57,000 deaths each year $[1,2]$. Despite declines in the incidence and mortality of colorectal cancer, survival following diagnosis has improved only modestly over the past 15 years [1-4]. However, early detection measures are available for colorectal cancer, and if caught in the earliest stage, more than $90 \%$ of patients will survive beyond five years.

Decreased survival is well documented among Blacks in relation to Whites, with most recent population-based studies showing a $30-50 \%$ higher rate of disease-specific mortality after diagnosis [5-13], and the largest racial/ethnic differentials seen among stage I and II cancers [5]. Of particular concern, the disparity in mortality rates between Blacks and Whites have widened over time $[14,15]$. The reasons for these differences are not well understood. The limited number of studies that have examined access and quality of cancer treatment, such as socioeconomic status [9-13,16], general treatment modalities [10], health insurance [13] and provider characteristics [9] have reported inconsistent results as to the extent to which these factors explained the Black-White differences in survival. Although comorbid illness and tumor aggressiveness have been shown to independently affect survival, their impact on racial/ethnic survival differences have not been well addressed.

There have been fewer population-based studies of colorectal survival in other racial/ethnic groups [5,6,17-20]. In a recent analysis of SEER data examining differences survival across detailed racial/ethnic groups, Chien et al found that, in addition to Blacks, higher hazard ratios for stage-adjusted colorectal cancer-specific deaths were seen among American Indians, Hawaiians, and Mexicans [5]. The authors speculated that the remaining decreased survival in these groups may be due to socioeconomic status and/or comorbidities. Choe et al found, in an analysis based on imputed SEER birthplace data, that foreign-born Asians were slightly more likely than US-born to present with advanced stage and have decreased stage-adjusted survival [17]. As colorectal cancer occurrence is known to be related to factors associated with living in a more developed country (sedentary lifestyle, high consumption of meats and saturated fats, and low consumption of fruits and vegetables $[21,22])$, disease burden in Hispanic and Asian racial/ethnic groups is expected to increase as they become acculturated to the lifestyle more common in the US [22-24]. It is important to also emphasize that "Asian" and "Hispanic" are very heterogeneous categories, each consisting of a variety of separate and discrete racial/ethnic groups. Thus, the understanding of issues related to colorectal cancer is a priority for these populations. Cur- rently, in SEER data, although detailed Hispanic origin is collected, more than half of Hispanic patients are coded as "other or not otherwise specified" for detailed Hispanic origin, thus analyses for detailed Hispanic subgroups is not advisable. However, detailed Asian categories are collected and are mostly accurate and reliable [25], thus analyses for detailed Asian subgroups is possible.

Our study aimed to address the gaps in understanding of factors associated with racial/ethnic survival patterns by jointly considering patient and clinical factors including sociodemographics, tumor characteristics, neighborhood SES, treatment, and comorbidities, in a representative and large population of Medicare-eligible patients (aged 65 and older, who comprise about $70 \%$ of all colorectal patients [26]). Using the SEER-Medicare linked database, our analyses extend those of Chien et al by including data on area-based socioeconomic status and comorbidities. We also considered the effects of these factors on survival within each of six racial/ethnic groups [27].

\section{Methods \\ Data Source}

We used the linked Surveillance, Epidemiology, and End Results (SEER) - Medicare database, which combines data from the NCI SEER Program of population-based registries that collect demographic, clinical, and vital status information for persons with cancer, with Medicare claims for covered health care services, including hospitalizations [28-30]. The registries in the SEER Program, at the time of this analysis, included the states of Connecticut, Hawaii, Iowa, New Mexico and Utah, and the metropolitan areas of Atlanta, Detroit, San Francisco/Oakland, Seattle/Puget Sound, San Jose/Monterey, and Los Angeles, representing approximately $14 \%$ of the US population [26]. The latter two registries joined the SEER program in 1992. Medicare is the primary source of health insurance for $97 \%$ of Americans age 65 years and older. All recipients are enrolled in Part A benefits, which cover inpatient care in hospitals and other facilities; ninety-five percent of beneficiaries also subscribe to Part $\mathrm{B}$, which covers additional services including physician services [29]. These are the sources of admissions data used in this analysis.

The linkage of SEER with Medicare data, which is based on a deterministic matching algorithm using social security number, name, sex, and date of birth [28], captured $93 \%$ of patients age 65 and older at diagnosis in the SEER database [29]. This analysis used data from the linkage conducted in 1999. Recipients under age 65 who received Medicare benefits for end-stage renal disease or for other reasons were excluded. 


\section{Study Subjects}

Patients living in a SEER catchment area and aged 65 and older when diagnosed with a microscopically-confirmed, first primary, malignant tumor of the colon or rectum (ICD-O-2 codes C180-C209, C260, excluding histologies 9590-9989) during the period January 1, 1992 through December 31, 1996 were included. This period of time was included for consistency with availability of physician claims data and 1990 Census data, which are provided as part of the linked database. We further excluded about $10 \%$ of cases that were coded as lymphomas, sarcomas, melanomas, carcinoids, or tumors of the squamous cell, appendix, or unspecified sites; those with invalid survival time (including those diagnosed at death or autopsy); those with unknown cause of death; and those of unknown or other race/ethnicity $(\mathrm{N}=208)$, leaving us a final sample of 41,901 subjects. The numbers of patients in each racial/ethnic group are shown in Table 1.

\section{Analytical Variables}

Race/ethnicity was classified according to the categories shown in the tables. These categories were created to be as specific as possible while preserving adequate numbers for stability of estimates. Information on race/ethnicity, age and year of diagnosis, SEER registry, marital status, tumor characteristics, and radiation were obtained from the SEER portion, or Patient Entitlement and Diagnosis Summary File (PEDSF), of the linked database. SEER registry staff members abstract these data elements from medical records at hospitals, doctor's offices and other facilities. In addition to the data originally obtained from SEER, the PEDSF also included data on area-based socioeconomic measures (poverty, percentage of high school graduates, median income) of the 1990 Census tract of residence as well as the urban/rural status of the county of residence.

Patient information on race and ethnicity were extracted from the SEER database, which are primarily based on patients' hospital medical records. Despite variable hospitals practices and policies in recording these information $[31,32]$, the quality of these data have been shown to be generally good [25,33]. Racial/ethnic categories were defined to be consistent with prior publications using SEER data $[6,19,34]$. Chinese, Japanese, and Filipinos were classified regardless of Hispanic ethnicity. Racial/ ethnic groups with fewer than 200 patients were excluded; these groups include American Indians/Alaskan Natives, Native Hawaiians and other Pacific Islanders, and other smaller Asian subgroups. Patients coded in the SEER data as Hispanic on the basis of surname only were not classified as Hispanic, because of prior research showing misclassification of surname-only classifications.
Census socioeconomic variables corresponding to the tract of patients' addresses at diagnosis are available in the linked SEER-Medicare data; more detailed geographic level measures are not available. Social epidemiologists have noted that while the sizes of the populations covered by census tract units are large and thus limited for conceptualizations of neighborhoods, they have also acknowledged that in the absence of better data, this level of geographical aggregation is acceptable and standard practice for examining neighborhood SES [35,36]. In fact, prior publications of national SEER data have examined contextual SES at an even broader level of geography [3741]. We examined measures of census tract SES (poverty, education, and income, as defined in Table 1) and also computed a composite measure (SES index) summing the quartiles of each individual measure. Quartiles are based on distributions of the entire study population. This SES index ranged from $1-4$, with 1 representing the highest SES quartile and 4 representing the lowest SES. Overall, there were 2937 (7\%) patients with missing SES data, ranging from $7 \%$ among Whites to $20 \%$ among Filipinos; it is likely that these patients could not be reliability geocoded to a census tract. In the absence of individual-level SES data in the cancer registry and Medicare databases, area-based SES measures are useful in this study for examining the impact of neighborhood socioeconomic status on cancer survival. These measures have been shown to be independently predictive of an array of health outcomes $[36,42-54]$. In this study, the area-based SES measures are not meant to serve as a proxy for individual-level SES.

We used claims information on inpatient hospitalizations and physicians visits occurring 12 months before and 4 months after diagnosis for classification of comorbidities using the Charlson comorbidity index $[55,56]$. The Charlson index assigns weights from 1 to 6 corresponding to disease severity, for 19 medical conditions. The weights are then summed to provide an overall score. For this analysis we excluded metastatic and in-situ colon and rectum cancers from the comorbidity index and adapted standard inclusion criteria, which specifies that physician admissions are valid comorbidities only if they occur on two or more claims more than 30 days apart $[30,57,58]$. Patients with no admissions records during this period were considered to have had no comorbidities. Medicare only requires claims data for care covered by fee-for-service, or indemnity, insurance; thus claims data for HMO enrollees were often not available in this database. We conducted the analyses that incorporate comorbidity information excluding those aged 65 at diagnosis [59] and did not find that our results changed from those including this group. As the numbers of patients with two or more comorbidities in most of the racial/ethnic groups are small (Table 1), we analyzed comorbidity in subsequent models as none versus any. 
Table I: Percent distribution of colorectal cancer patients, demographic and clinical characteristics by race/ethnicity $(\mathrm{N}=4 \mathrm{I}, 90 \mathrm{I})$, SEER, 1992-1996

\begin{tabular}{|c|c|c|c|c|c|c|}
\hline Characteristic & $\begin{array}{c}\text { Non-Hispanic } \\
\text { White } \\
N=34,164\end{array}$ & $\begin{array}{c}\text { Non-Hispanic } \\
\text { Black } \\
N=3,184\end{array}$ & $\begin{array}{l}\text { Hispanic } \\
N=2,061\end{array}$ & $\begin{array}{l}\text { Chinese } \\
N=88 I\end{array}$ & $\begin{array}{l}\text { Japanese } \\
N=1,116\end{array}$ & $\begin{array}{l}\text { Filipino } \\
\mathbf{N}=495\end{array}$ \\
\hline \multicolumn{7}{|l|}{ Gender } \\
\hline Male & 47 & 43 & 50 & 57 & 54 & 56 \\
\hline Female & 53 & 57 & 50 & 43 & 46 & 44 \\
\hline \multicolumn{7}{|l|}{ Year of diagnosis } \\
\hline 1992-93 & $4 I$ & 40 & 38 & 38 & 40 & 36 \\
\hline $1994-96$ & 59 & 60 & 62 & 62 & 60 & 64 \\
\hline \multicolumn{7}{|l|}{ SEER region ${ }^{2}$} \\
\hline SFBA & 15 & 14 & 22 & 50 & 10 & 35 \\
\hline Connecticut & 16 & 6 & 5 & 0 & 0 & I \\
\hline Detroit & 13 & 32 & 1 & I & 0 & 0 \\
\hline Hawaii & 1 & 0 & 0 & 13 & 60 & 33 \\
\hline lowa & 16 & 2 & I & -- & 0 & -- \\
\hline New Mexico & 3 & 1 & 18 & 0 & 0 & -- \\
\hline Seattle & 11 & 3 & 1 & 4 & 5 & 4 \\
\hline Utah & 3 & 0 & 2 & 0 & I & -- \\
\hline Atlanta & 4 & 13 & 1 & I & -- & 0 \\
\hline LA & 18 & 29 & 49 & 31 & 24 & 27 \\
\hline $20 \%+$ below poverty $(\mathrm{N}=38,964)$ & 7 & 52 & 25 & 20 & 9 & 11 \\
\hline \multicolumn{7}{|l|}{ Below poverty quartiles $3(N=38,964)$} \\
\hline I (highest SES) & 28 & 5 & 11 & 16 & 30 & 18 \\
\hline 2 & 27 & 7 & 16 & 22 & 28 & 29 \\
\hline 3 & 26 & 14 & 23 & 23 & 21 & 28 \\
\hline 4 (lowest SES) & 19 & 74 & 50 & 38 & 21 & 25 \\
\hline \multicolumn{7}{|l|}{ Non-HS quartiles ${ }^{4}(\mathrm{~N}=38,964)$} \\
\hline I (highest SES) & 28 & 6 & 11 & 20 & 19 & 11 \\
\hline 2 & 27 & 11 & 17 & 20 & 22 & 21 \\
\hline 3 & 26 & 15 & 19 & 21 & 28 & 22 \\
\hline 4 (lowest SES) & 18 & 69 & 53 & 39 & 31 & 47 \\
\hline \multicolumn{7}{|l|}{ Median income quartiles ${ }^{5}(\mathrm{~N}=38,964)$} \\
\hline I (highest SES) & 27 & 6 & 14 & 29 & 36 & 30 \\
\hline 2 & 26 & 11 & 23 & 26 & 32 & 37 \\
\hline 3 & 25 & 21 & 30 & 20 & 20 & 17 \\
\hline 4 (lowest SES) & 22 & 62 & 33 & 26 & 12 & 16 \\
\hline \multicolumn{7}{|l|}{ SES index ${ }^{6}$ quartiles $(N=38,964)$} \\
\hline I (highest SES) & 34 & 7 & 15 & 29 & 34 & 21 \\
\hline 2 & 21 & 7 & 13 & 13 & 20 & 24 \\
\hline 3 & 29 & 19 & 27 & 27 & 31 & 34 \\
\hline 4 (lowest SES) & 16 & 67 & 45 & 32 & 15 & 22 \\
\hline
\end{tabular}


Table I: Percent distribution of colorectal cancer patients, demographic and clinical characteristics by race/ethnicity $(\mathrm{N}=4 \mathrm{I}, 90 \mathrm{I})$, SEER, 1992-1996 (Continued)

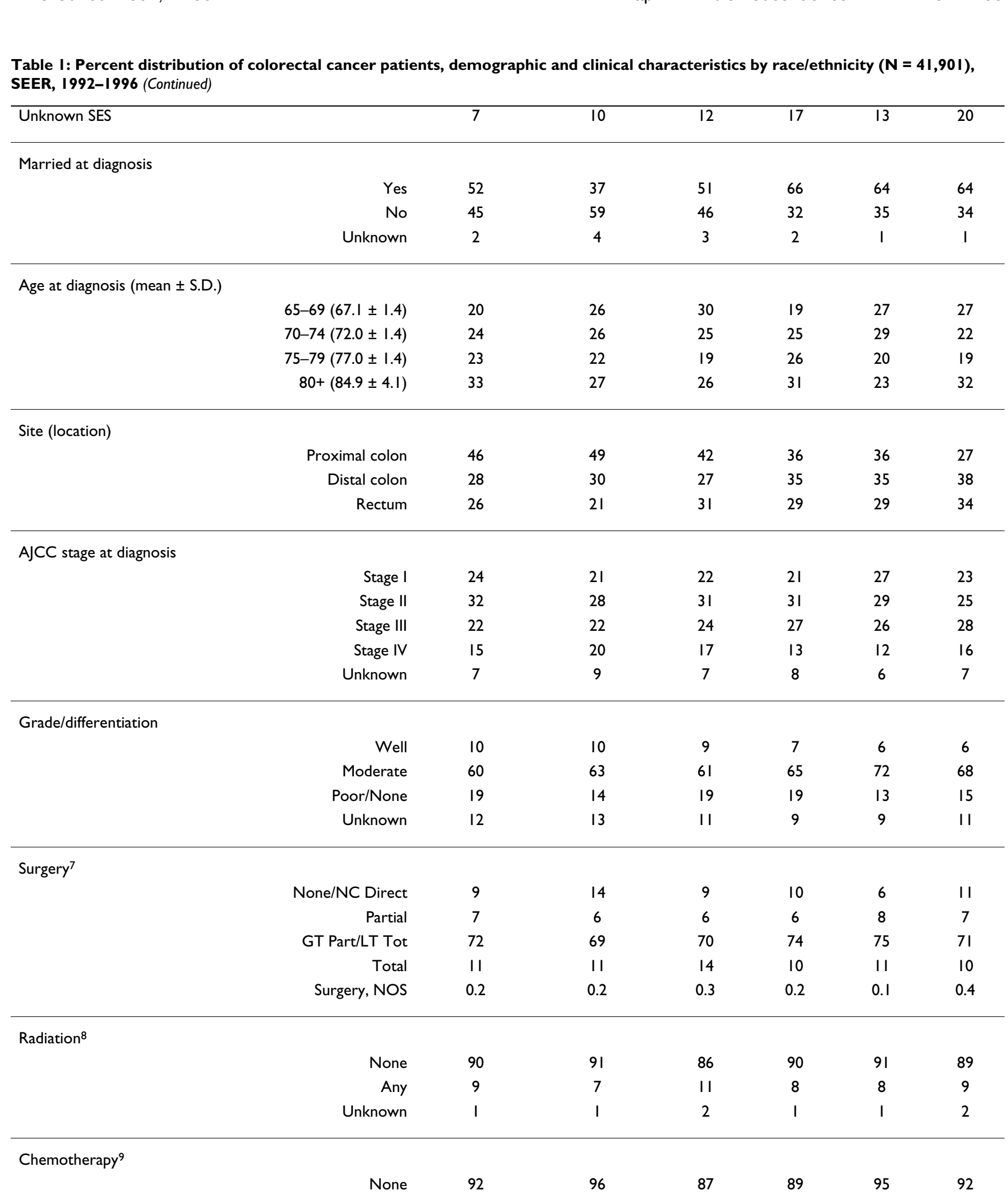

Surgery ${ }^{7}$

$\begin{array}{rcccccc}\text { None/NC Direct } & 9 & 14 & 9 & 10 & 6 & 11 \\ \text { Partial } & 7 & 6 & 6 & 6 & 8 & 7 \\ \text { GT Part/LT Tot } & 72 & 69 & 70 & 74 & 75 & 71 \\ \text { Total } & 11 & 11 & 14 & 10 & 11 & 10 \\ \text { Surgery, NOS } & 0.2 & 0.2 & 0.3 & 0.2 & 0.1 & 0.4\end{array}$

Radiation $^{8}$

$\begin{array}{rcccccc}\text { None } & 90 & 91 & 86 & 90 & 91 & 89 \\ \text { Any } & 9 & 7 & 11 & 8 & 8 & 9 \\ \text { Unknown } & 1 & 1 & 2 & 1 & 1 & 2\end{array}$

Chemotherapy 9

\begin{tabular}{rcccccc} 
None & 92 & 96 & 87 & 89 & 95 & 92 \\
Any & 8 & 4 & 13 & 11 & 5 & 8 \\
\hline$(\mathrm{N}=$ & 16 & 10 & 23 & 21 & 10 & 15 \\
& & & & & & \\
\hline cancer & 8 & 3 & 10 & 7 & 4 & 4
\end{tabular}

Received guideline treatment, stages II and III rectal cancer $(\mathrm{N}=4626)^{10}$ 
Table I: Percent distribution of colorectal cancer patients, demographic and clinical characteristics by race/ethnicity $(\mathrm{N}=4 \mathrm{I}, 90 \mathrm{I})$, SEER, 1992-1996 (Continued)

\begin{tabular}{|c|c|c|c|c|c|c|}
\hline $\begin{array}{l}\text { Received guideline treatment, stage III colon + stages II/III } \\
\text { rectal cancer }(N=I I, 566)^{10}\end{array}$ & 13 & 8 & 17 & 15 & 8 & 10 \\
\hline \multicolumn{7}{|l|}{ Comorbidity"I } \\
\hline None & 68 & 68 & 72 & 82 & 77 & 80 \\
\hline 1 & 22 & 19 & 19 & 14 & 16 & 13 \\
\hline 2 or more & 10 & 13 & 9 & 5 & 5 & 7 \\
\hline \multicolumn{7}{|c|}{$\begin{array}{l}\text { All of the comparisons are statistically significant across races/ethnicities (Chi-Square } \mathrm{p}<0.00 \mathrm{I}) \text {. } \\
\text { I Hispanic = } 2053 \text { Whites, } 8 \text { Blacks } \\
2 \text { SFBA: San Francisco Bay Area (San Francisco-Oakland \& San Jose-Monterey regions), LA: Los Angeles region } \\
3 \text { Percent of census tract residents living below poverty level } \\
{ }^{4} \text { Percent of persons age } 25+\text { years with less than } 12 \text { years of education in census tract } \\
{ }^{5} \text { Median household income in census tract } \\
{ }^{6} \text { SES index = summation of quartiles of poverty + high school graduate + median income } \\
7 \text { Colorectal cancer-directed surgery with or without radiation. NC = Non-cancer directed; GT Part/LT Tot = greater than partial/less than total; } \\
\text { Surgery, NOS = surgery, not otherwise specified } \\
{ }^{8} \text { Any radiation = beam, implants, isotopes, or combination; unknown = refused, recommended but don't know if administered, and unknown if } \\
\text { administered } \\
{ }^{9} \text { Chemotherapy assessed using data from the physician supplier files } \\
{ }^{10} \text { For stage III colon cancer, guideline treatment is receipt of surgery and chemotherapy; for stages II and III rectal cancer, guideline treatment is } \\
\text { receipt of surgery, chemotherapy, and radiation } \\
11 \text { Comorbidity measured with Charlson Index using data from physician supplier and inpatient hospitalization files }\end{array}$} \\
\hline
\end{tabular}

SEER-modified AJCC (American Joint Committee on Cancer) staging scheme, 3rd edition (1988+) was used to define tumor stage at diagnosis. AJCC stage is determined based on detailed information in SEER on extent of disease - tumor size, nodal involvement, and extent of metastasis. SEER registries collect information regarding treatment administered during the first four months postdiagnosis. For surgery, patients were classified as having received partial colectomy if they underwent segmental resection (cecectomy, appendectomy, sigmoidectomy, partial resection of transverse colon and flexures, ileocolectomy, enterocolectomy, and partial/subtotal colectomy), laser surgery, polypectomy, cryosurgery, or fulguration; and total/hemicolectomy if they received hemicolectomy or greater, all right/left and portion of transverse colectomy, total colectomy, non-specified colectomy, or colectomy plus partial/total removal of other organs. Information on receipt of radiation was obtained from SEER records; prior research has shown that SEER data alone on radiation is $>95 \%$ complete $[60,61]$. Chemotherapy was obtained from physician claims data (for a period of six months after diagnosis [62]) and coded into the categories shown in Table 1. Patients without physician claims data during this time period were coded as not having received chemotherapy. Warren et al previously documented that physician claims alone captures about $70 \%$ of chemotherapy administration for colon and rectal cancers [62]. In this cohort, the vast majority of patients (92\%) receiving chemotherapy received 5-fluorouracil. We also defined treatment as receiving guideline therapy according to the NIH consen- sus conference standards, which includes surgery plus adjuvant chemotherapy for stage III colon cancer and surgery plus adjuvant chemotherapy and radiation for stages II and III rectal cancer [63-67]. We have included each of these treatment modalities as separate variables into the models to assess their independent impact on survival; this practice is consistent with prior analyses based on cancer registry data [5,68-70]. In addition, within stage III colon and stages II and III rectal cancer, we have adjusted for one single variable representing receipt of guideline therapy.

\section{Follow-up}

Date and cause of death information were obtained from SEER. Registries conduct active and passive follow-up of cancer patients for vital status using linkages with state and national death indices, Centers for Medicare and Medicaid Services files, driver's license registration files, voter registration files, Social Security Administration files, national credit agency records, and other databases, as well as contact with patients, hospitals and physicians' offices. Through linkage of the SEER-Medicare data to a more recent version of the SEER public use data, patients in this analysis were followed for vital status through December 31, 1999, which is also the date of censoring for patients who were last known to be alive. Underlying cause of death was abstracted from death certificates, and deaths assigned International Classification of Disease Ninth Revision (ICD-9) codes 153.0-154.1 were identified as due to colon or rectal cancer. 


\section{Statistical Analyses}

The Mantel-Haenszel chi-square test was used to compute p-values for differences in distribution of patient and clinical characteristics across racial/ethnic groups. Five-year cause-specific survival probabilities and associated 95\% confidence intervals (CI) were computed based on Kaplan-Meier survival curves. This analysis focuses on causespecific (colorectal) survival as the outcome; however, racial/ethnic patterns were generally similar with the two types of outcomes - all-cause survival and colorectal specific-survival. Cox proportional hazards regression was used to compute relative rates of dying of colorectal cancer specifically and of all causes. Proportionality of hazards was checked graphically and confirmed use of the Cox regression models. Cells with less than five cases are not shown for privacy purposes. Models were computed with parameters representing each non-White racial/ethnic group to assess mortality difference compared to non-Hispanic Whites (Tables 2 (unadjusted survival), 3 (causespecific mortality), and 4 (all-cause mortality)); independent variables were included in turn to assess the relative impact on the racial/ethnic differences. Models were also computed for each racial/ethnic group (Tables 5 (cause-specific mortality) and 6 (all-cause mortality)) to assess the relative effects of the sociodemographic and clinical characteristics on mortality within groups. To assess whether differences in the parameter estimates were significant across racial/ethnic groups, we compared the log likelihood ratios for a main effects model with race/ ethnicity and the independent prognostic factors with a model containing an interaction term of race/ethnicity and the prognostic factor of interest.

Human subjects issues were reviewed and approved by the Northern California Cancer Center Institutional Review Board.

\section{Results \\ Characteristics of study population}

Table 1 shows the distribution of patient and clinical characteristics, by race/ethnicity. There were proportionally fewer males than females among Blacks and more males than females among Asians. Two-thirds of Blacks, about half of Hispanics, and one-third of Chinese lived in lower SES Census tracts. Whites and Japanese were least likely to be living in the lowest SES tracts. Chinese, Japanese, and Filipinos were most likely to be married, while Blacks were the least likely.

Whites and Blacks had higher proportions of proximal colon tumors than rectal cancers. In contrast, Filipinos had more distal and rectal tumors. Blacks, Hispanics, and Filipinos were more likely than other racial/ethnic groups to be diagnosed with stage III and IV disease, and Whites, Hispanics, and Chinese were more likely to be diagnosed with poorly or undifferentiated tumors. Proportionally more Blacks received no surgery or no cancer directed surgery $(14 \%)$. Only about $10 \%$ overall received radiation treatment, varying from $7 \%$ among Blacks to $11 \%$ among Hispanics. From $4-5 \%$ of Blacks and Japanese to $13 \%$ of Hispanics had chemotherapy. Relatively fewer Blacks and Japanese received guideline treatment for stage III colon cancer compared to Hispanics and Chinese, and relatively fewer Blacks, Japanese, and Filipinos received guideline treatment for stages II and III rectal cancer. Approximately one-third of Whites, Blacks, and Hispanics had one or more comorbid conditions, compared to smaller percentages in the other groups. Proportionally more Blacks had two or more comorbid conditions than the other groups, particularly the three Asian subgroups.

Table 2 shows unadjusted survival estimates by sex and race/ethnicity. Both Black males and females experienced

Table 2: Unadjusted survival estimates, by sex and race/ethnicity $(N=41,90$ I), SEER, I992-I 996

\begin{tabular}{|c|c|c|c|c|c|c|}
\hline Survival & $\begin{array}{l}\text { Non-Hispanic } \\
\text { White }\end{array}$ & $\begin{array}{l}\text { Non-Hispanic } \\
\text { Black }\end{array}$ & Hispanic & Chinese & Japanese & Filipino \\
\hline Males $(N=19,979)$ & 16,213 & 1,356 & 1,032 & 498 & 601 & 279 \\
\hline Colorectal cancer deaths, $\mathrm{N}(\%)$ & $5119(32)$ & 531 (39) & $375(36)$ & $154(3 \mid)$ & $157(26)$ & $88(32)$ \\
\hline $\begin{array}{l}\text { 5-Year colorectal survival }(95 \% \\
\mathrm{Cl})\end{array}$ & $0.65(0.64-0.65)$ & $0.55(0.52-0.58)$ & $0.60(0.56-0.63)$ & $0.67(0.62-0.7 I)$ & $0.7 \mathrm{I}(0.67-0.75)$ & $0.64(0.58-0.70)$ \\
\hline All cause deaths, $\mathrm{N}(\%)$ & $9116(56)$ & $854(63)$ & $569(55)$ & $252(5 \mathrm{I})$ & $293(49)$ & $153(55)$ \\
\hline 5 -Year all cause survival $(95 \% \mathrm{Cl})$ & $0.45(0.44-0.46)$ & $0.37(0.35-0.40)$ & $0.46(0.4 \mathrm{I}-0.49)$ & $0.51(0.46-0.56)$ & $0.53(0.49-0.57)$ & $0.47(0.4 \mathrm{I}-0.53)$ \\
\hline Females $(\mathrm{N}=21,922)$ & $|7,95|$ & $\mathrm{I}, 828$ & 1,029 & 383 & 515 & 216 \\
\hline Colorectal cancer deaths, N (\%) & $5865(33)$ & $723(40)$ & $33(32)$ & $132(34)$ & $146(28)$ & $66(31)$ \\
\hline $\begin{array}{l}\text { 5-Year colorectal survival } \\
(95 \% \mathrm{Cl})\end{array}$ & $0.64(0.63-0.65)$ & $0.55(0.53-0.58)$ & $0.64(0.60-0.67)$ & $0.62(0.57-0.67)$ & $0.69(0.64-0.73)$ & $0.68(0.60-0.74)$ \\
\hline All cause deaths, $\mathrm{N}(\%)$ & $9722(54)$ & $1125(62)$ & $538(52)$ & $185(48)$ & $226(44)$ & $99(46)$ \\
\hline 5 -Year all cause survival $(95 \% \mathrm{Cl})$ & $0.47(0.47-0.48)$ & $0.39(0.37-0.4 I)$ & $0.48(0.45-0.5 \mathrm{I})$ & $0.52(0.47-0.57)$ & $0.57(0.52-0.61)$ & $0.54(0.46-0.60)$ \\
\hline
\end{tabular}


Table 3: Relative rates (and 95\% confidence intervals) of dying of colorectal cancer for each racial/ethnic group (relative to nonHispanic Whites), SEER, 1992-1996

\begin{tabular}{|c|c|c|c|c|c|c|}
\hline \multirow[t]{2}{*}{ Variables in model } & \multirow{2}{*}{$\begin{array}{c}\text { Non-Hispanic } \\
\text { Black } \\
\mathbf{N}=3,009\end{array}$} & \multicolumn{2}{|c|}{$\begin{array}{c}\text { Hispanic } \\
N=1,95 \text { I }\end{array}$} & \multirow[t]{2}{*}{$\begin{array}{l}\text { Chinese } \\
N=85 I\end{array}$} & \multirow[t]{2}{*}{$\begin{array}{l}\text { Japanese } \\
N=1,094\end{array}$} & \multirow[t]{2}{*}{$\begin{array}{l}\text { Filipino } \\
N=479\end{array}$} \\
\hline & & $\begin{array}{c}\text { Male } \\
\mathbf{N}=1,032\end{array}$ & $\begin{array}{c}\text { Female } \\
\mathbf{N}=1,029\end{array}$ & & & \\
\hline I. Race/ethnicity & $1.33(1.26-1.42)$ & $1.16(1.04-1.29)$ & $0.98(0.88-1.10)$ & $0.98(0.87-I . I I)$ & $0.79(0.70-0.88)$ & $0.99(0.84-1.16)$ \\
\hline $\begin{array}{l}\text { 2. Race/ethnicity + } \\
\text { sociodemographics I }\end{array}$ & $1.32(1.24-1.41)$ & $1.12(1.00-1.26)$ & $1.02(0.91-1.15)$ & $1.06(0.93-1.19)$ & $0.94(0.82-1.09)$ & $1.09(0.92-1.30)$ \\
\hline $\begin{array}{l}\text { 3. Race/ethnicity }+ \\
\text { sociodemographics \& disease } \\
\text { characteristics }^{2}\end{array}$ & $1.26(1.18-1.34)$ & $1.01(0.90-1.13)$ & $0.93(0.82-1.04)$ & $1.02(0.90-1.16)$ & $0.97(0.84-1.12)$ & $0.96(0.81-1.13)$ \\
\hline $\begin{array}{l}\text { 4. Race/ethnicity + } \\
\text { sociodemographics, disease } \\
\text { characteristics, \& treatment }^{3}\end{array}$ & $1.21(1.14-1.29)$ & $1.01(0.90-1.14)$ & $0.94(0.83-1.06)$ & $0.97(0.86-1.10)$ & $0.98(0.85-1.13)$ & $0.91(0.76-1.07)$ \\
\hline $\begin{array}{l}\text { 5. Race/ethnicity + } \\
\text { sociodemographics, disease } \\
\text { characteristics, treatment, \& } \\
\text { education }\end{array}$ & $1.16(1.09-1.24)$ & $0.98(0.87-1.10)$ & $0.92(0.81-1.04)$ & $0.95(0.84-1.08)$ & $0.96(0.83-1.11)$ & $0.88(0.74-1.05)$ \\
\hline $\begin{array}{l}\text { 6. Race/ethnicity }+ \\
\text { sociodemographics, disease } \\
\text { characteristics, treatment, \& } \\
\text { income }\end{array}$ & $1.17(1.09-1.25)$ & $0.99(0.89-1.12)$ & $0.93(0.83-1.05)$ & $0.96(0.85-1.09)$ & $0.98(0.85-1.12)$ & $0.90(0.76-1.07)$ \\
\hline $\begin{array}{l}\text { 7. Race/ethnicity + } \\
\text { sociodemographics, disease } \\
\text { characteristics, treatment, \& } \\
\text { poverty }\end{array}$ & $1.16(1.09-1.25)$ & $0.99(0.88-1.11)$ & $0.93(0.83-1.05)$ & $0.96(0.84-1.08)$ & $0.98(0.85-1.12)$ & $0.90(0.76-1.06)$ \\
\hline $\begin{array}{l}\text { 8. Race/ethnicity + } \\
\text { sociodemographics, disease } \\
\text { characteristics, treatment, \& } \\
\text { comorbidities }\end{array}$ & $1.21(1.14-1.29)$ & $1.01(0.90-1.13)$ & $0.94(0.83-1.05)$ & $0.97(0.86-1.10)$ & $0.98(0.85-1.13)$ & $0.91(0.77-1.08)$ \\
\hline
\end{tabular}

I sociodemographic factors = age and marital status at diagnosis, sex, year of diagnosis, and SEER region

2 disease characteristics $=$ stage, grade, site

3 treatment $=$ surgery, radiation, chemotherapy

decreased 5-year survival compared to other groups. Other notable racial/ethnic variations in survival include decreased disease-specific survival among Hispanic males. Some heterogeneity in survival among Asian subgroups was evident: Filipino males and Chinese females experienced slightly decreased disease-specific and overall survival.

\section{Factors associated with survival/mortality}

Race/ethnic mortality relative to Whites

Table 3 shows the relative rates of dying of colorectal cancer for each racial/ethnic group compared to Whites. Racial/ethnic patterns, relative to Whites, were similar between males and females and are thus combined, with the exception of Hispanics, for whom gender differences, in relation to Whites, were evident and thus presented separately. Compared to Whites, colorectal cancer-specific mortality rates were 33\% higher among Blacks and 16\% higher among Hispanic males. Mortality rates among Japanese were lower than Whites, while mortality among Hispanic females, Chinese and Filipinos was comparable to Whites. Among Blacks, adjusting for disease character- istics (primarily stage) reduced the hazard ratio from 1.32 to 1.26 , and while adjusting independently for education level, poverty, and income further reduced the hazard ratio, mortality among Blacks was still 16\% significantly higher than Whites. Among Hispanic males, adjustment for disease characteristics (primarily stage) appeared to account for their higher mortality compared to Whites. Among Japanese, the significantly lower mortality rate compared to Whites was partially attributable to disease characteristics but mostly to sociodemographic factors (primarily SEER region). Comorbidity did not affect racial/ethnic differences in colorectal cause-specific mortality rates.

Table 4 shows the relative rates of dying of any cause for each racial/ethnic group compared to Whites. The 23\% higher rate of death among Blacks compared to Whites was partially attributable to disease characteristics, socioeconomic status, and treatment (to a lesser extent), although the all-cause mortality rate among Blacks remained significantly higher than the rate among Whites even after adjusting for all of these factors simultaneously. 
Table 4: Relative rates (and $95 \%$ confidence intervals) of dying of any cause for each racial/ethnic group (relative to non-Hispanic Whites), SEER, 1992-1996

\begin{tabular}{|c|c|c|c|c|c|c|}
\hline \multirow[t]{2}{*}{ Variables in model } & \multirow{2}{*}{$\begin{array}{c}\text { Non-Hispanic } \\
\text { Black } \\
N=3,009\end{array}$} & \multicolumn{2}{|c|}{ Hispanic } & \multirow{2}{*}{$\begin{array}{l}\text { Chinese } \\
N=1,094\end{array}$} & \multirow{2}{*}{$\begin{array}{l}\text { Japanese } \\
\mathbf{N}=479\end{array}$} & \multirow[t]{2}{*}{ Filipino } \\
\hline & & $N=1,95 I$ & $\mathbf{N}=85$ I & & & \\
\hline & & Male $N=1,032$ & Female $N=1,029$ & & & \\
\hline I. Race/ethnicity & $1.23(1.18-1.30)$ & $1.01(0.92-1.10)$ & $0.97(0.89-1.07)$ & $0.88(0.80-0.97)$ & $0.78(0.72-0.85)$ & $0.95(0.84-1.08)$ \\
\hline $\begin{array}{l}\text { 2. Race/ethnicity }+ \\
\text { sociodemographics! }\end{array}$ & $1.23(1.17-1.29)$ & $1.03(0.94-1.13)$ & $1.03(0.94-1.13)$ & $0.95(0.86-1.05)$ & $0.95(0.85-1.06)$ & $1.05(0.92-1.20)$ \\
\hline $\begin{array}{l}\text { 3. Race/ethnicity }+ \\
\text { sociodemographics \& disease } \\
\text { characteristics }^{2}\end{array}$ & $1.18(1.13-1.24)$ & $0.96(0.88-1.06)$ & $0.95(0.87-1.04)$ & $0.92(0.83-1.02)$ & $0.97(0.87-1.09)$ & $0.97(0.85-1.11)$ \\
\hline $\begin{array}{l}\text { 4. Race/ethnicity + } \\
\text { sociodemographics, disease } \\
\text { characteristics, \& treatment }^{3}\end{array}$ & 1.14 (1.08-1.20) & $0.97(0.89-1.06)$ & $0.96(0.87-1.05)$ & $0.88(0.80-0.97)$ & $0.98(0.88-1.09)$ & $0.93(0.8 I-1.06)$ \\
\hline $\begin{array}{l}\text { 5. Race/ethnicity + } \\
\text { sociodemographics, disease } \\
\text { characteristics, treatment, \& } \\
\text { education }\end{array}$ & $1.09(1.04-1.15)$ & $0.93(0.84-1.02)$ & $0.93(0.85-1.02)$ & $0.86(0.78-0.95)$ & $0.96(0.86-1.07)$ & $0.90(0.78-1.03)$ \\
\hline $\begin{array}{l}\text { 6. Race/ethnicity + } \\
\text { sociodemographics, disease } \\
\text { characteristics, treatment, \& } \\
\text { income }\end{array}$ & $1.09(1.04-1.16)$ & $0.94(0.86-1.04)$ & $0.95(0.86-1.04)$ & $0.87(0.79-0.96)$ & $0.98(0.88-1.09)$ & $0.93(0.8 I-1.06)$ \\
\hline $\begin{array}{l}\text { 7. Race/ethnicity + } \\
\text { sociodemographics, disease } \\
\text { characteristics, treatment, \& } \\
\text { poverty }\end{array}$ & $1.08(1.03-1.14)$ & $0.94(0.86-1.03)$ & $0.95(0.86-1.04)$ & $0.87(0.78-0.96)$ & $0.97(0.87-1.09)$ & $0.92(0.80-1.05)$ \\
\hline $\begin{array}{l}\text { 8. Race/ethnicity + } \\
\text { sociodemographics, disease } \\
\text { characteristics, treatment, \& } \\
\text { comorbidities }\end{array}$ & $1.14(1.09-1.20)$ & $0.96(0.88-1.05)$ & $0.95(0.87-1.05)$ & $0.91(0.82-1.00)$ & $0.99(0.89-1.11)$ & $0.95(0.83-1.08)$ \\
\hline
\end{tabular}

\footnotetext{
I sociodemographic factors = age and marital status at diagnosis, sex, year of diagnosis, and SEER region

2 disease characteristics $=$ stage, grade, site

3 treatment $=$ surgery, radiation, chemotherapy
}

Comorbidity did not affect the all-cause mortality difference between Black and White colorectal cancer patients. Chinese and Japanese experienced significantly lower allcause mortality compared to Whites; for both groups, their more favorable mortality rates were attributable to sociodemographic factors. There were no differences in all-cause mortality between Hispanics, Filipinos, and Whites.

Focusing on those stages of cancer for which guidelines exist for standard of care (i.e., stage III colon and stages II/ III rectal cancer, data not shown), Blacks had 10\% higher rate of death due to all causes compared to Whites (hazard ratio $=1.10,95 \%$ CI $1.00-1.21)$. This hazard rate ratio ranged from 1.05 to 1.07 and was statistically non-significant after including each of the SES variables (education, income, or poverty) into the model. Similarly, for colorectal cancer specific survival, Blacks had 15\% higher rate of death compared to Whites (hazard ratio $=1.15,95 \% \mathrm{CI}$ 1.03-1.28), which was completely accounted for by adjusting for each SES variable. Adjusting for guideline treatment did not alter the small difference in all-cause or colorectal specific survival between Blacks and Whites.
Race/ethnic-specific mortality

Proportional hazards modeling was conducted separately for each racial/ethnic group and the adjusted relative rates are shown in Tables 5 (disease-specific mortality) and 6 (all-cause mortality). For disease-specific mortality, among Whites, older age, male gender, single marital status, advanced stage, advanced grade, rectal site (compared to distal), having no surgery, having no chemotherapy, residence in New Mexico or Utah (relative to San Francisco Bay Area (SFBA)), and having one or more comorbidities were all independently associated with higher mortality following colorectal cancer diagnosis. Only the SES variable education showed a statistically significant gradient of association with mortality among Whites. Among Blacks, higher mortality was seen among patients of older age, advanced stage and grade, who had no surgery, no radiation, or no chemotherapy. None of the SES variables were significantly associated with mortality among Blacks, although poverty showed non-significantly protective effects, and higher education showed non-significantly adverse effects. Among Hispanics, increased mortality was associated with advanced age, male gender, single marital status, advanced stage and 
Table 5: Adjusted' relative rates (and $95 \%$ confidence intervals) of dying of colorectal cancer associated with selected demographic and clinical characteristics, within race/ethnic group, SEER, 1992-1996, $\mathrm{N}=40,2092$

\begin{tabular}{|c|c|c|c|c|c|c|c|c|c|c|c|c|c|c|c|c|c|c|}
\hline \multirow{3}{*}{$\begin{array}{l}\text { Characteristic } \\
\text { (referent } \\
\text { group) }\end{array}$} & \multicolumn{3}{|c|}{$\begin{array}{l}\text { Non-Hispanic } \\
\text { White }\end{array}$} & \multicolumn{3}{|c|}{$\begin{array}{c}\text { Non-Hispanic } \\
\text { Black }\end{array}$} & \multicolumn{3}{|c|}{ Hispanic } & \multicolumn{3}{|c|}{ Chinese } & \multicolumn{3}{|c|}{ Japanese } & \multicolumn{3}{|c|}{ Filipino $N=479$} \\
\hline & $N=32,825$ & $N=3,009$ & $N=85 I$ & $N=32,825$ & $N=1,094$ & $N=479$ & & & & & & & & & & & & \\
\hline & Adjusted RR & \multicolumn{2}{|c|}{$95 \% \mathrm{Cl}$} & Adjusted RR & \multicolumn{2}{|c|}{$95 \% \mathrm{Cl}$} & Adjusted RR & \multicolumn{2}{|c|}{$95 \% \mathrm{Cl}$} & Adjusted RR & \multicolumn{2}{|c|}{$95 \% \mathrm{Cl}$} & Adjusted RR & \multicolumn{2}{|c|}{$95 \% \mathrm{Cl}$} & Adjusted RR & \multicolumn{2}{|c|}{$95 \% \mathrm{Cl}$} \\
\hline \multicolumn{19}{|l|}{ Age (65-69) } \\
\hline $70-74$ & 1.08 & 1.02 & -1.15 & 1.28 & 1.09 & -1.51 & 1.21 & 0.97 & -1.51 & 1.14 & 0.76 & -1.70 & 1.25 & 0.89 & -1.75 & 0.76 & 0.43 & -1.32 \\
\hline 75-79 & 1.18 & 1.11 & -1.25 & 1.28 & 1.08 & -1.52 & 1.35 & 1.07 & -1.70 & 1.11 & 0.74 & -1.67 & 1.62 & 1.12 & -2.33 & 1.60 & 0.99 & -2.59 \\
\hline $80+$ & 1.53 & 1.44 & -1.62 & 1.35 & 1.14 & -1.59 & 1.79 & 1.43 & -2.23 & 1.99 & 1.34 & -2.95 & 1.77 & 1.24 & -2.53 & 1.60 & 1.00 & -2.57 \\
\hline \multicolumn{19}{|l|}{ Gender (female) } \\
\hline Male & 1.06 & 1.02 & -1.11 & 1.02 & 0.90 & -1.15 & 1.25 & 1.05 & -1.48 & 1.17 & 0.90 & -1.54 & 0.94 & 0.73 & -1.21 & 1.26 & 0.86 & -1.85 \\
\hline \multicolumn{19}{|l|}{$\begin{array}{l}\text { Marital status } \\
\text { (ever married) }\end{array}$} \\
\hline Single & 1.14 & 1.09 & -1.19 & 0.98 & 0.86 & -1.12 & 1.24 & 1.04 & -1.46 & 1.33 & 1.00 & -1.76 & 1.21 & 0.92 & -1.60 & 0.91 & 0.62 & -1.34 \\
\hline \multicolumn{19}{|l|}{$\begin{array}{l}\text { Diagnosis year } \\
\text { (1992-1993) }\end{array}$} \\
\hline \multirow{2}{*}{\multicolumn{19}{|c|}{ AJCC stage (I) }} \\
\hline & & & & & & & & & & & & & & & & & & \\
\hline ॥ & 2.33 & 2.12 & -2.55 & 2.65 & 2.02 & -3.47 & 1.93 & 1.37 & -2.72 & 3.74 & 1.94 & -7.23 & 2.37 & 1.32 & -4.24 & 2.60 & 1.14 & -5.90 \\
\hline III & 5.62 & 5.13 & -6.14 & 4.63 & 3.54 & -6.04 & 3.89 & 2.77 & -5.47 & 8.15 & 4.25 & -15.62 & 7.34 & 4.27 & -12.61 & 4.52 & 2.07 & -9.85 \\
\hline IV & 23.69 & 21.67 & -25.90 & 20.36 & 15.70 & -26.40 & 17.04 & 12.23 & -23.74 & 35.12 & 18.14 & -68.02 & 41.39 & 23.68 & -72.36 & 18.22 & 8.36 & -39.70 \\
\hline Unknown & 3.63 & 3.25 & -4.06 & 3.25 & 2.40 & -4.42 & 2.76 & 1.76 & -4.34 & 3.77 & 1.81 & -7.85 & 2.45 & 1.15 & -5.23 & 3.49 & 1.39 & -8.73 \\
\hline \multicolumn{19}{|l|}{ Grade (well) } \\
\hline Moderate & 1.22 & 1.12 & -1.32 & 1.21 & 0.95 & -1.54 & 1.28 & 0.91 & -1.80 & 2.46 & 1.24 & -4.91 & 0.90 & 0.43 & -1.88 & 0.93 & 0.43 & -2.01 \\
\hline Poor/None & 1.86 & 1.70 & -2.03 & 1.90 & 1.45 & -2.49 & 1.98 & 1.38 & -2.85 & 3.65 & 1.79 & -7.45 & 1.25 & 0.58 & -2.72 & 1.23 & 0.53 & -2.84 \\
\hline Unknown & 1.29 & 1.17 & -1.43 & 1.26 & 0.95 & -1.68 & 1.20 & 0.80 & -1.79 & 1.92 & 0.88 & -4.23 & 0.69 & 0.29 & -1.62 & 0.28 & 0.10 & -0.80 \\
\hline Site (rectal) & & & & & & & & & & & & & & & & & & \\
\hline Distal & 0.90 & 0.84 & -0.95 & 0.86 & 0.72 & -1.03 & 0.91 & 0.72 & -1.16 & 0.98 & 0.69 & -1.37 & 0.99 & 0.70 & -1.39 & 1.11 & 0.70 & -1.77 \\
\hline Proximal & 1.01 & 0.96 & -1.06 & 0.91 & 0.77 & -1.07 & 0.89 & 0.72 & -1.11 & 1.04 & 0.74 & -1.46 & 0.89 & 0.63 & -1.26 & 1.35 & 0.83 & -2.19 \\
\hline $\begin{array}{l}\text { Surgery (none/ } \\
\text { NC direct) }\end{array}$ & & & & & & & & & & & & & & & & & & \\
\hline $\begin{array}{r}\text { GT Partial LT } \\
\text { Total }\end{array}$ & 0.30 & 0.28 & -0.32 & 0.28 & 0.23 & -0.33 & 0.30 & 0.23 & -0.39 & 0.25 & 0.16 & -0.38 & 0.18 & 0.11 & -0.29 & 0.19 & 0.11 & -0.33 \\
\hline Partial & 0.27 & 0.24 & -0.32 & 0.30 & 0.20 & -0.44 & 0.17 & 0.09 & -0.33 & 0.66 & 0.29 & -1.49 & 0.13 & 0.05 & -0.32 & 0.66 & 0.22 & -1.96 \\
\hline Total & 0.37 & 0.34 & -0.40 & 0.41 & 0.33 & -0.51 & 0.38 & 0.28 & -0.52 & 0.41 & 0.24 & -0.70 & 0.21 & 0.12 & -0.37 & 0.16 & 0.08 & -0.33 \\
\hline Radiation (none) & & & & & & & & & & & & & & & & & & \\
\hline Any & 0.98 & 0.92 & -1.05 & 0.78 & 0.63 & -0.97 & 1.00 & 0.77 & -1.29 & 0.99 & 0.62 & -1.59 & 1.21 & 0.78 & -1.88 & 0.79 & 0.41 & -1.51 \\
\hline $\begin{array}{l}\text { Chemotherapy } \\
\text { (none) }\end{array}$ & & & & & & & & & & & & & & & & & & \\
\hline Any & 0.89 & 0.83 & -0.95 & 0.64 & 0.49 & -0.85 & 0.75 & 0.60 & -0.94 & 0.76 & 0.52 & -1.10 & 0.91 & 0.57 & -1.46 & 1.14 & 0.67 & -1.94 \\
\hline $\begin{array}{l}\text { SEER } \\
\text { region(SFBA) }\end{array}$ & & & & & & & & & & & & & & & & & & \\
\hline Atlanta & 0.97 & 0.88 & -1.08 & 0.75 & 0.60 & -0.94 & 0.25 & 0.06 & -1.02 & 1.20 & 0.28 & -5.13 & - & & - & & & - \\
\hline Connecticut & 0.97 & 0.90 & -1.04 & 0.81 & 0.60 & -1.09 & 0.51 & 0.32 & -0.82 & 1.58 & 0.21 & -12.07 & 0.00 & 0.00 & - & 1.64 & 0.34 & -7.94 \\
\hline Detroit & 0.98 & 0.91 & -1.06 & 0.91 & 0.76 & -1.09 & 1.05 & 0.48 & -2.30 & 0.31 & 0.04 & -2.33 & 4.24 & 0.53 & -33.64 & 9.86 & 1.09 & -89.23 \\
\hline Hawaii & 0.84 & 0.68 & -1.03 & 1.43 & 0.35 & -5.89 & 1.12 & 0.16 & -8.15 & 0.66 & 0.41 & -1.04 & 1.21 & 0.80 & -1.83 & 0.75 & 0.48 & -1.17 \\
\hline lowa & 0.94 & 0.87 & -1.03 & 0.92 & 0.54 & -1.58 & 1.32 & 0.58 & -3.04 & - & & - & 1.54 & 0.20 & -11.74 & - & & - \\
\hline LA & 0.98 & 0.91 & -1.05 & 0.84 & 0.70 & -1.01 & 0.74 & 0.60 & -0.91 & 1.24 & 0.92 & -1.66 & 1.32 & 0.87 & -2.02 & 1.26 & 0.81 & -1.98 \\
\hline New Mexico & 1.13 & 1.00 & -1.28 & 0.93 & 0.43 & -2.02 & 0.88 & 0.67 & -1.17 & & & - & & & - & - & & - \\
\hline Seattle & 1.02 & 0.94 & -1.11 & 0.95 & 0.67 & -1.35 & 0.74 & 0.36 & -1.55 & 0.93 & 0.48 & -1.82 & 0.99 & 0.53 & -1.85 & 0.67 & 0.25 & -1.81 \\
\hline
\end{tabular}


Table 5: Adjusted' relative rates (and $95 \%$ confidence intervals) of dying of colorectal cancer associated with selected demographic and clinical characteristics, within race/ethnic group, SEER, 1992-1996, N = 40,2092 (Continued)

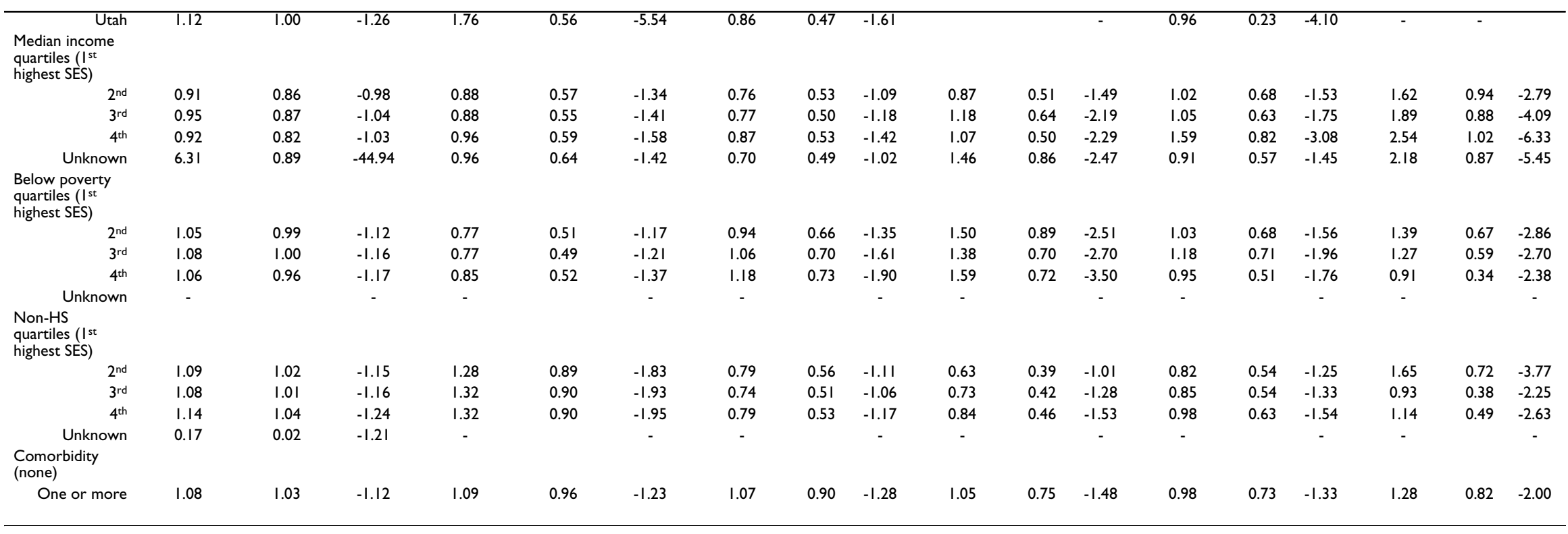

Adjusted for the other factors in the table.

2Excludes patients with unknown marital status and/or unknown radiation 
Table 6: Adjusted' relative rates (and $95 \%$ confidence intervals) of dying of any cause associated with selected demographic and clinical characteristics, within race/ethnic group, SEER, I 992-1996, N = 40,2092

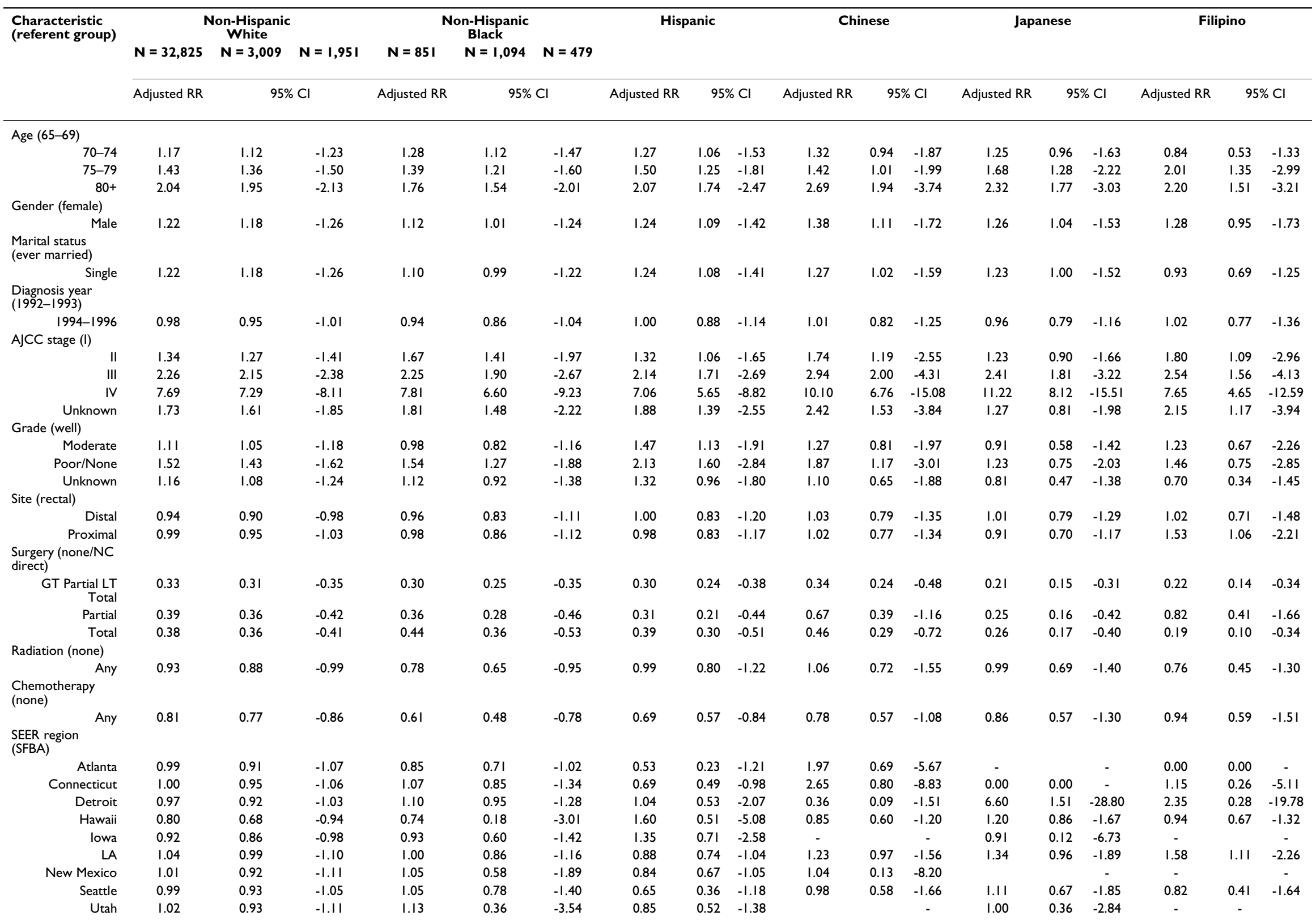


Table 6: Adjusted' relative rates (and $95 \%$ confidence intervals) of dying of any cause associated with selected demographic and clinical characteristics, within race/ethnic group, SEER, 1992-1996, N = 40,2092 (Continued)

Median income

highest SES)

$\begin{array}{lll}2^{\text {nd }} & 0.94 & 0.90 \\ 3^{\text {rd }} & 0.96 & 0.90 \\ 4^{\text {th }} & 0.92 & 0.85 \\ & 7.10 & 1.00\end{array}$

\section{Below poverty}

quartiles (Ist
highest SES)

highest SES) $\quad 2^{\text {nd }} \quad 1.04$

$\begin{array}{rccc}2^{\text {nd }} & 1.04 & 1.00 & -1.09 \\ 3^{\text {rd }} & 1.06 & 1.00 & -1.13 \\ 4^{\text {th }} & 1.09 & 1.02 & -1.18 \\ \text { Unknown } & - & & - \\ \begin{array}{c}\text { Non-HS quartiles } \\ \text { (Ist highest SES) }\end{array} & & & \end{array}$

(15thighest SES)

$\begin{array}{rlll}2^{\text {nd }} & 1.06 & 1.02 & -1.11 \\ 3^{\text {rd }} & 1.09 & 1.03 & -1.15 \\ 4^{\text {th }} & 1.13 & 1.06 & -1.20 \\ \quad \begin{array}{l}\text { Unknown } \\ \text { Comorbidity }\end{array} & 0.16 & 0.02 & -1.13 \\ \text { (none) } & & & \\ \quad \text { One or more } & 1.50 & 1.46 & -1.55\end{array}$

$-1.5$

1.41

1.28

$-1.55$

1.34

$1.17-1.53$

1.35

1.53

Adjusted for the other factors in the table.
2Excludes patients with unknown marital status and/or unknown radiation 
grade, no surgery, and no chemotherapy. Compared to residents in the SFBA, Hispanics in Atlanta, Connecticut, and LA experienced decreased mortality (statistically significant for Connecticut and LA). Among Chinese, statistically significant factors associated with increased mortality were advanced age, single marital status, advanced stage and grade, and no surgery. Among Japanese, the only factors significantly associated with increased mortality were advanced age, advanced stage, and no surgery. Among Filipinos, increased mortality was significantly associated with advanced stage, no surgery, and living in the lowest income neighborhood. None of the SES variables were associated with mortality among Hispanics, Chinese, and Japanese.

Stage had the biggest impact on mortality among all racial/ethnic groups, followed by surgery. However, variations in the importance of the other factors were evident across groups. For example, male gender was associated with increased mortality in Whites and Hispanics, but not among Blacks, Chinese, Japanese, and Filipinos. Single marital status was associated with increased mortality among Whites and Hispanics, and suggested for Chinese and Japanese. Histologic grade was a significant predictive factor of mortality in all groups except for Japanese and Filipinos. Radiation was associated with mortality only among Blacks. Chemotherapy decreased mortality in most groups except Filipinos. Geographic differences in mortality were also apparent, with relatively higher mortality among Whites in New Mexico and Utah; and lower mortality among Hispanics in Atlanta, Connecticut, and LA. Significantly increased mortality was seen with lower income among Filipinos. Little variation in effect was seen among the racial/ethnic groups for poverty, except for slightly increased mortality among Whites and non-significantly protective effect among Blacks. Significant associations with education were seen only among Whites. The tests for significant parameter effects across racial/ethnic-specific colorectal mortality models (ie, interaction of parameter with race/ethnicity) showed that the effects of marital status, stage, and chemotherapy were statistically significant ( $\mathrm{p}<.025, \mathrm{p}<.01, \mathrm{p}<.01$, respectively) across the racial/ethnic groups.

Some differences in factors associated with all-cause mortality (Table 6) compared to cause-specific mortality were evident for each racial/ethnic group, but the most notable difference was the considerably higher impact of comorbidity on mortality, with patients with one or more comorbid conditions having 34\% (Hispanics) to $73 \%$ (Filipinos) higher mortality than patients without any comorbidities. Another notable difference in all-cause mortality compared to colorectal-specific mortality is the higher mortality among males compared to females across nearly all racial/ethnic groups for all-cause mortal- ity, whereas higher mortality among males for colorectalcancer specific mortality was observed only among Whites and Hispanics.

\section{Discussion}

Our results, based on a large and representative cohort, show consistently increased mortality (i.e., decreased survival) among Blacks, compared to Whites, that is partially but not completely explained by demographic, disease, treatment, and SES characteristics. This racial/ethnic disparity was evident for mortality due to colorectal cancer as an underlying cause of death, as well as all-cause mortality, although the magnitude of the disparity was larger for colorectal cancer mortality. However, within stage III colon and stages II/III rectal cancer, for which guideline treatments are established, survival differences between Blacks and Whites were considerably smaller and completely explained by SES. We also found decreased survival among Hispanic males that was completely attributable to their being more likely to be diagnosed with advanced stage cancer, and increased survival among Japanese that was due in part to their being more likely to be diagnosed with early stage disease and their place of residence. Our study extends prior population-based racial/ethnic studies of colorectal cancer survival by including additional explanatory factors, including information on comorbidities, radiation, chemotherapy, and area-based SES. In an analysis based on national SEER data, Chien et al. found persistently decreased stageadjusted survival among certain racial/ethnic groups and postulated that the residual differences were attributable to SES and/or comorbidities [5]. Using SEER data linked to Medicare claims, we were able to evaluate the impact of these factors, plus additional treatment information, on racial/ethnic differences in survival, and found that although SES had some impact on Black-White differences in survival, comorbidities and treatment did not affect the racial/ethnic differences in survival, at least among the Medicare-eligible population. In fact, the presence of comorbidities had minimal impact on colorectal cancer-specific survival in general, and only among nonHispanic Whites. As expected, comorbidities were more strongly associated with all-cause survival across the racial/ethnic groups. However, we cannot discount the possibility that more detailed measures of comorbidity (e.g., specific conditions or specific combinations of conditions) or a more comprehensive data collection method (e.g., through medical record review [71]) may have more significant impacts on survival. Our results confirm, in a national Medicare population, those from the NCI Black/ White Cancer Survival Study conducted in the mid-1980's [11], that the Black-White differential in colorectal survival is partly attributable to stage and SES, but some proportion of the difference remains unexplained. We further found that this pattern was true for all-cause survival as 
well. A recent review and meta-analysis of 10 studies on colon cancer survival by $\mathrm{Du}$ et al. showed that the adjusted hazard ratio for Blacks compared to Whites was 1.14 (1.00-1.29) for all-cause mortality and 1.13 (1.011.28) for colon cancer-specific mortality [72]. Among those studies that adjusted simultaneously for age, comorbidity, SES, and treatment, the estimates were 1.16 (1.03$1.32)$ and 1.30 (1.01-1.67), respectively [72]. These estimates are similar in magnitude to those found in our study, 1.14 (1.09-1.20) and 1.21 (1.14-1.29), respectively, with our results showing slightly tighter confidence intervals.

Thus far, it appears that the only studies showing statistically equal stage-adjusted survival between Blacks and Whites are those done in a VA setting [4,73], suggesting that there may be attributes of the VA system (equal access to screening and treatment, uniform treatment) or its population (similar SES, equal utilization) that are unique from the general population. An analysis comparing lung and colon cancer outcomes between Black and White VA patients who received uniform evaluation and treatment showed that cancer outcomes were similar despite lower SES (individual-level) among Blacks [74]. Shavers and Brown synthesized several studies examining racial/ethnic disparities in colorectal cancer treatment and found that population-based studies tended to find significant racial/ ethnic differences in treatment, whereas studies showing no racial/ethnic differences tended to be non-populationbased, from a single clinic or locality, or of VA populations [75]. A recent study of a cohort of insured patients found that Black-White differences in survival were explained primarily by stage and receipt of surgery [76]. In a conceptual framework illustrating potential barriers to the receipt of optimal cancer treatment, Shavers and Brown advocated the importance of "structural barriers", which include presence and type of insurance coverage, institutional and geographic factors [75]. In fact, a number of recent, population-based studies have demonstrated a modest but independent effect of surgeon and hospital characteristics $[8,77]$ and of specific types of health care coverage [10], but, to our knowledge, these factors have not been evaluated for their impact on racial/ ethnic differentials in survival following colorectal cancer.

The increased survival of Japanese compared to other race/ethnic groups and other Asian subgroups has been noted in other studies $[5,19,20]$. We found that about half of the survival difference between Japanese and Whites was due to earlier stage at diagnosis among Japanese, the other half due to the greater proportion of Japanese living in Hawaii and the increased survival in Hawaii seen in some racial/ethnic groups. Choe et al found, in a survival analysis of national SEER data (with imputed nativity data) that US-born Asians experienced more favorable survival than foreign-born Asians [17]; as only $28 \%$ of Japanese (in California) are foreign-born [78] and they tend to be the most acculturated of other Asian subgroups, future research might focus on specific factors associated with being US-born Asian, or Japanese in particular, that confer a survival advantage. In a previous paper, we noted decreased stage-adjusted survival among Filipino males [19]; evidently, the poor survival was limited to both earlier years of diagnosis and younger Filipino men, thus, this pattern was not seen in this analysis.

Our race/ethnicity-specific survival models also revealed differential effects of some of the covariates on colorectalspecific and all-cause survival within each racial/ethnic group. Surprisingly, the area-based SES variables did not appear to be associated with colorectal cancer nor allcause survival in most racial/ethnic groups. Only the measures poverty and education demonstrated marginally significant effects on survival among Whites, and income among Filipinos. The differential effect of marital status is also interesting: whereas single patients tended to have decreased survival than those who were married, this was not true for Blacks nor Filipinos. The quality of marital status information in the cancer registry is uncertain, so these results should be cautiously interpreted, but the beneficial effects of being married on cancer survival has been previously explored and is hypothesized to be due to greater spousal social support [79]. We also observed significantly decreased all-cause survival among males compared to females in nearly all racial/ethnic groups. As this gender difference was not seen for colorectal-specific survival among most racial/ethnic groups, this finding suggests that, relative to females, male colorectal patients experienced decreased survival due to causes of death other than colorectal cancer.

There were also differences in the effects of tumor characteristics and treatment. For example, histologic grade, reflecting tumor aggressiveness, did not appear to impact survival among Japanese and Filipinos. Although having any extent of surgical resection was uniformly associated with increased survival across all groups, a beneficial effect of radiation was only seen among Blacks. Chemotherapy was associated with increased survival in all groups, but not in Asians. These racial/ethnic differences in treatment impact on survival may reflect differential distributions of stage and colorectal cancer subsite among race/ethnic groups $[63,75]$, or of a differential selection by physicians of healthier patients to receive these treatments $[71,80]$. In addition, because our measures of surgery, radiation, and chemotherapy are crude, the differences may also reflect differences in the quality of treatment. Further study examining survival patterns within specific stage and subsite, and incorporating more specific treatment data would be helpful. Overall, the results from 
these race/ethnicity-specific analyses support the value of evaluating each group on its own, as this type of analysis may reveal patterns that can result in more targeted and meaningful prevention efforts and strategies for improving survival for each group.

Stage remains the single most independently predictive factor on survival following diagnosis of colorectal cancer across and within racial/ethnic groups. For persons aged 50 or older, the American Cancer Society recommends one of five screening schedules, depending on the modality (fecal occult blood test (FOBT) yearly, flexible sigmoidoscopy or barium enema every 5 years, or colonoscopy every 10 years) [81]; however, data based on the California Health Interview Survey showed that only $53 \%$ of respondents reported having had an FOBT in the past year or sigmoidoscopy/colonoscopy in the past 5 years [82]. Moreover, Latinos reported lower screening for colorectal cancer (37\%) compared to $56.4 \%$ among Whites [82]. Research on promoters and barriers to cancer screening consistently show that, among Asians and Latinos, screening is lower among recent migrants with limited English proficiency [82-87]. There is ongoing research to examine strategies to increase screening in different cultures [88]. Since early detection could potentially reduce some of these differences in survival, particularly among Hispanic men, it is clearly important to learn about barriers to screening among specific communities and to elucidate the most effective strategies for promoting screening in these communities.

Although our study provided a comprehensive evaluation of multiple factors in relation to survival across and within race/ethnic groups, our results may be limited by the quality of some of the SEER and Medicare data. For example, research of race/ethnic misclassification in medical admissions and registry data shows that although there is high consistency between self-report and hospital data for Whites and Blacks, consistency is lower for other groups, in particular Hispanics, American Indians, and certain Asian subgroups $[25,33,89]$. Our study may also be compromised by completeness of surgery, radiation, and, in particular, chemotherapy data. Comparisons of surgery and radiation recorded in SEER with other sources (Medicare admissions, physician survey) show that registry data are, for the most part, complete and do not vary greatly with regards to race/ethnicity [60,61,90-92]. Warren et al showed that physician claims data capture about $70 \%$ of the chemotherapy administered among colorectal cancer patients [62]; however, the prevalence of receipt of chemotherapy and of guideline treatment are lower than those seen in other studies $[64,65,76]$ raising concerns about some under-ascertainment of chemotherapy in our data. Thus, we cannot discount the idea that our results, particularly the Black-White differences in survival, may be affected by completeness in our treatment data, particularly if it is differential across racial/ethnic groups. Our analyses could benefit from the addition of potentially useful information on insurance, hospital and physicians characteristics to investigate institutional factors that create unequal access to medical care $[8,9,77,93,94]$. Additionally, although information on colorectal cancer screening is theoretically available from Medicare claims data, insurance coverage for these screening modalities went into effect only recently $[95,96]$ and the completeness may be further compromised by how providers bill for these procedures. Furthermore, we included patients diagnosed with colorectal cancer during the years 19921997 to allow for observation of a reasonable amount of time between diagnosis and follow-up; however, racial/ ethnic survival patterns, particularly between Blacks and Whites, may have changed during this time. Data from the SEER registries showed that while 5-year survival improved among White males and females and Black females between 1992-1997 and 1997-2002, it has worsened slightly among Black males. Thus the survival disparity between Black and White males has increased [14], making the implications of our analysis even more noteworthy.

\section{Conclusion}

Despite the inherent limitations in the data source used in the analyses, our study has strengths in being a comprehensive analysis of colorectal cancer survival - both in the enhanced inclusion of specific racial/ethnic groups and prognostic factors, gained from linkage to Medicare and Census data. We found evidence that, in the older Medicare population, racial/ethnic disparities in colorectal cancer survival may be reduced by increasing access to screening. However, among Blacks, survival disparities compared to Whites and other racial/ethnic groups persist even after accounting for a comprehensive set of sociodemographic, clinical, and treatment characteristics. Williams has proposed that the persistently worse health outcomes among Blacks may be attributable to broader societal discrimination in neighborhoods (i.e., residential segregation) and in health care delivery (i.e., institutional discrimination) $[97,98]$. With regards to colorectal cancer survival, additional research in areas that have received less attention, such as structural and institutional barriers $[75,77]$, and of factors that have been proposed recently as having significant impacts on survival, including physical activity $[99,100]$ and vitamin $D[101-103]$, is necessary to identify the factors and mechanisms leading to the poorer outcomes among US Blacks. Population-based cancer registry data continue to be an invaluable resource for identifying and addressing racial/ethnic health disparities, however, expansion of the data through collection of additional data items and/or linkage to other data sources [104] is necessary for looking beyond traditional explana- 
tions, particularly if we hope to be able to reduce disparities in cancer outcomes.

\section{Competing interests}

The author(s) declare that they have no competing interests.

\section{Authors' contributions}

SLG designed the study, obtained the data, provided oversight of the data analyses, and drafted the manuscript. COM participated in the design of the study, the interpretation of the results, and helped to draft the manuscript. AS and SS participated in the design of the study and performed the statistical analyses. WS participated in the design of the study and helped to draft the manuscript. All authors read and approved the final manuscript.

\section{Acknowledgements}

This study used the linked SEER-Medicare database. The interpretation and reporting of these data are the sole responsibility of the authors. The authors acknowledge the efforts of the Applied Research Program, NCl; the Office of Research, Development and Information, CMS; Information Management Services (IMS), Inc.; and the Surveillance, Epidemiology, and End Results (SEER) Program tumor registries in the creation of the SEERMedicare database. The funding for this study and the collection of part of the cancer incidence data were supported under contracts N0I-CN-65I 07 and NOI-PC-35I 36 with the National Cancer Institute, National Institutes of Health, and with support of the California Cancer Registry, a project of the Cancer Surveillance Section, California Department of Health Services, under subcontracts 100089I and N02-PC-15105 with the Public Health Institute, and by the Centers for Disease Control and Prevention's National Program of Cancer Registries under agreement U55/CCR92 1930-02 awarded to the Public Health Institute. The content of this publication does not necessarily reflect the views or policies of the US Department of Health and Human Services or the California Department of Health Services, nor does mention of trade names, commercial products, or organizations imply endorsement by the US Government or state of California. The authors thank Dr. Joan Warren and the SEER-Medicare team for their invaluable assistance and input into this analysis and manuscript. The authors also thank Rita Leung, Ashley Dunham, Hui Shen, Laura McClure, Kathleen Torres, and Dr. Sherry Wren for their contributions to this study.

\section{References}

I. American Cancer Society: Cancer Facts and Figures 2007. Atlanta, American Cancer Society; 2007.

2. Ries LAG, Melbert D, Krapcho M, Mariotto A, Miller BA, Feuer EJ, Clegg L, Horner MJ, Howlader N, Eisner MP, Reichman M, Edwards BK: SEER Cancer Statistics Review, 1975-2004, based on November 2006 SEER data submission, posted to the SEER web site. 2007 [http://seer.cancer.gov/csr//975 2004/]. Bethesda, MD

3. Chu KC, Tarone RE, Chow WH, Hankey BF, Ries LA: Temporal patterns in colorectal cancer incidence, survival, and mortality from 1950 through 1990. J Natl Cancer Inst 1994, 86(13):997-1006.

4. Rabeneck L, EI-Serag HB, Davila JA, Sandler RS: Outcomes of colorectal cancer in the United States: no change in survival (1986-1 997). Am J Gastroenterol 2003, 98(2):47I-477.

5. Chien C, Morimoto LM, Tom J, Li Cl: Differences in colorectal carcinoma stage and survival by race and ethnicity. Cancer 2005, 104(3):629-639.

6. Clegg LX, Li FP, Hankey BF, Chu K, Edwards BK: Cancer survival among US whites and minorities. Arch Intern Med 2002, 162:1985-1993.
7. Cooper GS, Yuan Z, Rimm AA: Racial disparity in the incidence and case-fatality of colorectal cancer: analysis of 329 United States counties. Cancer Epidemiol Biomarkers Prev 1997, 6(4):283-285.

8. Hodgson DC, Fuchs CS, Ayanian JZ: Impact of patient and provider characteristics on the treatment and outcomes of colorectal cancer. J Natl Cancer Inst 200 I, 93(7):50 I-5 I5.

9. Hodgson DC, Zhang W, Zaslavsky AM, Fuchs CS, Wright WE, Ayanian JZ: Relation of hospital volume to colostomy rates and survival for patients with rectal cancer. J Natl Cancer Inst 2003, 95(10):708-716.

10. Lee-Feldstein A, Feldstein PJ, Buchmueller T: Health care factors related to stage at diagnosis and survival among Medicare patients with colorectal cancer. Med Care 2002, 40(5):362-374.

II. Mayberry RM, Coates RJ, Hill HA, Click LA, Chen VW, Austin DF, Redmond CK, Fenoglio-Preiser CM, Hunter CP, Haynes MA, et al:: Determinants of black/white differences in colon cancer survival. J Natl Cancer Inst 1995, 87(22): 1686-I693.

12. Polednak AP: Poverty, comorbidity, and survival of colorectal cancer patients diagnosed in Connecticut. J Health Care Poor Underserved 200I, I 2(3):302-3I0.

13. Roetzheim RG, Pal N, Gonzalez EC, Ferrante JM, Van Durme DJ, Krischer JP: Effects of health insurance and race on colorectal cancer treatments and outcomes. Am J Public Health 2000, 90(II): 1746-1754.

14. Irby K, Anderson WF, Henson DE, Devesa SS: Emerging and widening colorectal carcinoma disparities between Blacks and Whites in the United States (1975-2002). Cancer Epidemiol Biomarkers Prev 2006, 15(4):792-797.

15. Polite BN, Dignam JJ, Olopade OI: Colorectal cancer model of health disparities: understanding mortality differences in minority populations. J Clin Oncol 2006, 24(14):2179-2I87.

16. Marcella S, Miller JE: Racial differences in colorectal cancer mortality. The importance of stage and socioeconomic status. J Clin Epidemiol 200I, 54(4):359-366.

17. Choe JH, Koepsell TD, Heagerty PJ, Taylor VM: Colorectal cancer among Asians and Pacific Islanders in the U.S.: Survival disadvantage for the foreign-born. Cancer Detect Prev 2005.

18. Gilliland FD, Hunt WC, Key CR: Trends in the survival of American Indian, Hispanic, and Non-Hispanic white cancer patients in New Mexico and Arizona, 1969-1994. Cancer 1998, 82(9): 1769-1783.

19. Lin SS, Clarke CA, Prehn AW, Glaser SL, West DW, O'Malley CD: Survival differences among Asian subpopulations in the United States after prostate, colorectal, breast, and cervical carcinomas. Cancer 2002, 94(4): I I75-I I82.

20. Pagano IS, Morita SY, Dhakal S, Hundahl SA, Maskarinec G: Time dependent ethnic convergence in colorectal cancer survival in Hawaii. BMC Cancer 2003, 3(1):5.

21. Schottenfeld D, Winawer SJ: Cancer of the large intestine. In Cancer Epidemiology and Prevention Edited by: Schottenfeld D, JF Fraumenia J. Oxford, Oxford University Press; 1996:813-840.

22. Whittemore AS, Wu-Williams AH, Lee M, Zheng S, Gallagher RP, Jiao DA, Zhou L, Wang XH, Chen K, Jung D, et al.: Diet, physical activity, and colorectal cancer among Chinese in North America and China. J Natl Cancer Inst 1990, 82(I I):915-926.

23. Prehn A, Lin S, Clarke C, Packel L, Lum R, Lui S, Harper C, Lee M, Glaser S, West D: Cancer Incidence in Chinese, Japanese and Filipinos in the US and Asia 1988-1992. Union City, CA, Northern California Cancer Center; 1999.

24. Whittemore AS: Colorectal cancer incidence among Chinese in North America and the People's Republic of China: variation with sex, age and anatomical site. Int J Epidemiol 1989, 18(3):563-568.

25. Gomez SL, Glaser SL: Misclassification of race/ethnicity in a population-based cancer registry. Cancer Causes and Control 2006, 17:77|-78I.

26. Surveillance Epidemiology and End Results web site: SEER Registries. [http://seer.cancer.gov/registries/]. http://wwwseer.ims.nci.nih.gov/AboutSEER.html

27. Comstock RD, Castillo EM, Lindsay SP: Four-year review of the use of race and ethnicity in epidemiologic and public health research. Am J Epidemiol 2004, I 59(6):6I|-6| 9 .

28. Potosky AL, Riley GF, Lubitz JD, Mentnech RM, Kessler LG: Potential for cancer related health services research using a linked 
Medicare-tumor registry database. Med Care 1993, $3 I(8): 732-748$.

29. Warren JL, Klabunde CN, Schrag D, Bach PB, Riley GF: Overview of the SEER-Medicare data: content, research applications, and generalizability to the United States elderly population. Med Care 2002, 40(8 Suppl):IV-3-I8.

30. SEER-Medicare Linked Database, Health Services and Economics, Cancer Control \& Population Sciences, Institute NC: . [http://health services.cancer.gov/seermedicare/].

31. Gomez SL, Le GM, West DW, Satariano WA, O'Connor L: Hospital policy and practice regarding the collection of data on race, ethnicity, and birthplace. Am J Public Health 2003, 93(10): 1685-1688.

32. Polednak AP: Collecting information on race, Hispanic ethnicity, and birthplace of cancer patients: policies and practices in Connecticut hospitals. Ethn Dis 2005, 1 5(I):90-96.

33. Clegg LX, Reichman ME, Hankey BF, Miller BA, Lin YD, Johnson NJ, Schwartz SM, Bernstein L, Chen VW, Goodman MT, Gomez SL, Graff Jj, Lynch CF, Lin CC, Edwards BK: Quality of race, Hispanic ethnicity, and immigrant status in population-based cancer registry data: implications for health disparity studies. Cance Causes Control 2007

34. Miller BA, Kolonel LN, Bernstein L, Young Jr JL, Swanson GM, West D, Key CR, Liff JM, Glover CS, Alexander GA, al. : Racial/Ethnic Patterns of Cancer in the United States, 1988-1992. Volume NIH Pub. No. 96-4104. Bethesda, MD , National Cancer Institute; 1996.

35. Kawachi I, Berkman LF: Neighborhoods and Health. New York, Oxford University Press; 2003.

36. Krieger N, Chen JT, Waterman PD, Rehkopf DH, Yin R, Coull BA Race/ethnicity and changing US socioeconomic gradients in breast cancer incidence: California and Massachusetts, 1978 2002 (United States). Cancer Causes Control 2006, I7(2):2 I7-226.

37. Du XL Fang S, Coker AL Sanderson M, Aragaki C, Cormier JN, Xing Y, Gor BJ, Chan W: Racial disparity and socioeconomic status in association with survival in older men with local/regional stage prostate carcinoma: findings from a large communitybased cohort. Cancer 2006, I06(6): I276-I 285.

38. Singh GK, Miller BA, Hankey BF: Changing area socioeconomic patterns in U.S. cancer mortality, 1950-1998: Part II--Lung and colorectal cancers. J Natl Cancer Inst 2002, 94( I 2):916-925.

39. Singh GK, Miller BA, Hankey BF, Edwards BK: Area socioeconomic variations in U.S. cancer incidence, mortality, stage, treatment, and survival, 1975-1999. NCl Cancer Surveillance Monograph Series, Number 4 Bethesda, MD, National Cancer Institute 2003.

40. Singh GK, Miller BA, Hankey BF, Edwards BK: Persistent area socioeconomic disparities in U.S. incidence of cervical cancer, mortality, stage, and survival, 1975-2000. Cancer 2004, I0 I(5): 105।-1057.

4I. Singh GK, Miller BA, Hankey BF, Feuer EJ, Pickle LW: Changing area socioeconomic patterns in U.S. cancer mortality, 1950 1998: Part I--All cancers among men. J Natl Cancer Inst 2002, 94(I 2):904-9|5.

42. Krieger N: Socioeconomic data in cancer registries. Am J Public Health 200I, 91 ( I): 156-157.

43. Krieger N, Chen JT, Waterman PD, Soobader MJ, Subramanian SV, Carson R: Geocoding and monitoring of US socioeconomic inequalities in mortality and cancer incidence: does the choice of area-based measure and geographic level matter?: the Public Health Disparities Geocoding Project. Am J Epidemiol 2002, I 56(5):47|-482.

44. Chandola T, Bartley M, Wiggins R, Schofield P: Social inequalities in health by individual and household measures of social position in a cohort of healthy people. J Epidemiol Community Health 2003, 57(I):56-62.

45. Diez Roux AV: Investigating neighborhood and area effects on health. Am J Public Health 200I, 91(II): 1783-1789.

46. Diez Roux AV: The study of group-level factors in epidemiology: rethinking variables, study designs, and analytical approaches. Epidemiol Rev 2004, 26: I04-III.

47. Haan M, Kaplan GA, Camacho T: Poverty and health. Prospective evidence from the Alameda County Study. Am J Epidemiol I 987, I 25(6):989-998.

48. Kubzansky LD, Subramanian SV, Kawachi I, Fay ME, Soobader MJ, Berkman LF: Neighborhood Contextual Influences on Depressive Symptoms in the Elderly. Am J Epidemiol 2005.
49. Pickett KE, Pearl M: Multilevel analyses of neighbourhood socioeconomic context and health outcomes: a critical review. J Epidemiol Community Health 200I, 55(2): I I I-I 22.

50. Robert SA: Socioeconomic position and health: the independent contribution of community socioeconomic context. Annual Review of Sociology 1999, 25:489-516.

5I. Robert SA, Strombom I, Trentham-Dietz A, Hampton JM, McElroy JA Newcomb PA, Remington PL: Socioeconomic risk factors for breast cancer: distinguishing individual- and communitylevel effects. Epidemiology 2004, I 5(4):442-450.

52. Subramanian SV: The relevance of multilevel statistical methods for identifying causal neighborhood effects. Soc Sci Med 2004, 58(1 0): 1961-1967.

53. Winkleby MA, Cubbin C: Influence of individual and neighbourhood socioeconomic status on mortality among black, Mexican-American, and white women and men in the United States. J Epidemiol Community Health 2003, 57(6):444-452.

54. Yen IH, Kaplan GA: Neighborhood social environment and risk of death: multilevel evidence from the Alameda County Study. Am J Epidemiol 1999, I49(10):898-907.

55. Charlson ME, Pompei P, Ales KL, MacKenzie CR: A new method of classifying prognostic comorbidity in longitudinal studies: development and validation. J Chronic Dis 1987, 40(5):373-383.

56. Klabunde CN, Warren JL, Legler JM: Assessing comorbidity using claims data: an overview. Med Care 2002, 40(8 Suppl):IV-26-35.

57. Klabunde CN, Potosky AL, Legler JM, Warren JL: Development of a comorbidity index using physician claims data. J Clin Epidemiol 2000, 53(I 2): I 258-1267.

58. SEER-Medicare Linked Database, Health Services and Economics, Cancer Control \& Population Sciences, Institute NC: SEER-Medicare: Calculation of Comorbidity Weights. [http://healthserv ices.cancer.gov/seermedicare/program/comorbidity.html]

59. Bach PB, Cramer LD, Warren JL, Begg CB: Racial differences in the treatment of early-stage lung cancer. N Engl J Med 1999 , 34I(I6): I I 98-I 205

60. Cress RD, Zaslavsky AM, West DW, Wolf RE, Felter MC, Ayanian JZ: Completeness of information on adjuvant therapies for colorectal cancer in population-based cancer registries. Med Care 2003, 4I(9): 1006-1012.

61. Virnig BA, Warren JL, Cooper GS, Klabunde CN, Schussler N, Freeman J: Studying radiation therapy using SEER-Medicarelinked data. Med Care 2002, 40(8 Suppl):IV-49-54.

62. Warren JL, Harlan LC, Fahey A, Virnig BA, Freeman JL, Klabunde CN, Cooper GS, Knopf KB: Utility of the SEER-Medicare data to identify chemotherapy use. Med Care 2002, 40(8 Suppl):IV-556I.

63. NIH consensus conference: Adjuvant therapy for patients with colon and rectal cancer. Jama 1990, 264(I I): |444- I 450.

64. Potosky AL, Harlan LC, Kaplan RS, Johnson KA, Lynch CF: Age, sex, and racial differences in the use of standard adjuvant therapy for colorectal cancer. J Clin Oncol 2002, 20(5): I | 92-I 202.

65. Cronin DP, Harlan L, Potosky AL, Clegg LX, Stevens JL, Mooney MM: Patterns of care for adjuvant therapy in a random population-based sample of patients diagnosed with colorectal cancer. Am J Gastroenterology 2006, I0 I:2308-23 I8.

66. National Cancer Institute NIH: Colon Cancer (Physician Data Query (PDQ)) Treatment. Health Professional Version. [http://www.cancer.gov/cancertopics/pdg/treatment/colon/Health Professional].

67. National Cancer Institute NIH: Rectal Cancer (Physician Data Query (PDQ)) Treatment. Health Professional Version. [http://www.cancer.gov/cancertopics/pdq/treatment/rectal/Health Professional]

68. O'Malley CD, Le GM, Glaser SL, Shema SJ, West DW: Socioeconomic status and breast carcinoma survival in four racial/ ethnic groups: a population-based study. Cancer 2003, 97(5): |303-|3||

69. Robbins AS, Koppie TM, Gomez SL, Parikh-Patel A, Mills PK: Differences in Prognostic Factors and Survival among White Men and Asian Men with Prostate Cancer, California, 1995-2004. Cancer in press.

70. Robbins AS, Yin D, Parikh-Patel A: Differences in Prognostic Factors and Survival among White Men and Black Men with Prostate Cancer, California, 1995-2004. Am J Epidemiol 2007, 166(I):7|-78. 
71. Lemmens VE, Janssen-Heijnen ML, Verheij CD, Houterman S, Repelaer van Driel OJ, Coebergh JW: Co-morbidity leads to altered treatment and worse survival of elderly patients with colorectal cancer. Br J Surg 2005, 92(5):6I5-623.

72. Du XL, Meyer TE, Franzini L: Meta-analysis of racial disparities in survival in association with socioeconomic status among men and women with colon cancer. Cancer 2007, 109(II):2161-2170.

73. Dominitz JA, Samsa GP, Landsman P, Provenzale D: Race, treatment, and survival among colorectal carcinoma patients in an equal-access medical system. Cancer 1998, 82(I 2):23|2-2320.

74. Akerley WL 3rd, Moritz TE, Ryan LS, Henderson WG, Zacharski LR: Racial comparison of outcomes of male Department of Veterans Affairs patients with lung and colon cancer. Arch Intern Med 1993, I53(14): 168|-1688.

75. Shavers VL, Brown ML: Racial and ethnic disparities in the receipt of cancer treatment. Journal of the National Cancer Institute 2002, 94(5):334-357.

76. Doubeni CA, Field TS, Buist DS, Korner EJ, Bigelow C, Lamerato L, Herrinton L, Quinn VP, Hart G, Hornbrook MC, Gurwitz JH, Wagner $\mathrm{EH}$ : Racial differences in tumor stage and survival for colorectal cancer in an insured population. Cancer 2007 109(3):612-620

77. Baldwin LM, Dobie SA, Billingsley K, Cai Y, Wright GE, Dominitz JA, Barlow W, Warren JL, Taplin SH: Explaining black-white differences in receipt of recommended colon cancer treatment. J Natl Cancer Inst 2005, 97( 16): | 2 I I- 1220.

78. Asian Pacific American Legal Center of Southern California, Asian Law Caucus, National Asian Pacific American Legal Consortium: The Diverse Face of Asians and Pacific Islanders in California. Asian \& Pacific Islander Demographic Profile. Los Angeles, CA ; 2005

79. Lai H, Lai S, Krongrad A, Trapido E, Page JB, McCoy CB: The effect of marital status on survival in late-stage cancer patients: an analysis based on surveillance, epidemiology, and end results (SEER) data, in the United States. Int J Behav Med 1999 6(2): $150-176$

80. Lemmens VE, van Halteren AH, Janssen-Heijnen ML, Vreugdenhil G, Repelaer van Driel OJ, Coebergh JW: Adjuvant treatment for elderly patients with stage III colon cancer in the southern Netherlands is affected by socioeconomic status, gender, and comorbidity. Ann Oncol 2005, 16(5):767-772.

81. American Cancer Society: ACS Cancer Detection Guidelines. [http://www.cancer.org/docroot/PED/ contenPED 2 3X ACS Cancer Detection Guidelines 36.asp?sitea rea=PED].

82. Babey SH, Ponce NA, Etzioni DA, Spencer BA, Brown ER, Chawla N Cancer screening in California: racial and ethnic disparities persist. UCLA Center for Health Policy Research Policy Brief 2003.

83. Goel MS, Wee CC, McCarthy EP, Davis RB, Ngo-Metzger Q, Phillips RS: Racial and ethnic disparities in cancer screening. The importance of foreign birth as a barrier to care. J Gen Intern Med 2003, I8:1028-1035.

84. Lee M: Breast and cervical cancer early detection in Chinese American women. Proceedings to Cancer Concerns for Asian Americans and Pacific Islanders (June 27-29, 1998, San Francisco, CA). Asian American and Pacific Islander Journal of Health 1998, 6:35I-357.

85. McBride MR, Pasick RJ, Stewart S, Tuason N, Sabogal F, Duenas G: Factors associated with cervical cancer screening among Filipino women in California. Proceedings to Cancer Concerns for Asian Americans and Pacific Islanders (June 27-29, 1998, San Francisco, CA). Asian American and Pacific Islander Journal of Health 1998, 6:358-367.

86. McPhee SJ, Bird JA, Davis T, Ha NT, Jenkins CN, Le B: Barriers to breast and cervical cancer screening among VietnameseAmerican women. Am J Prev Med 1997, I3(3):205-2I3.

87. McPhee SJ, Stewart S, Brock KC, Bird JA, Jenkins CN, Pham GQ: Factors associated with breast and cervical cancer screening practices among Vietnamese American women. Cancer Detect Prev 1997, 2 I (6):5 10-52 I.

88. Theisen $C$ : In different cultures, cancer screening presents challenges. J Natl Cancer Inst 2004, 96(I): 10-12.

89. Gomez SL, Glaser SL, Kelsey JL, Lee MM, Sidney S: Inconsistencies between self-reported ethnicity and ethnicity recorded in a health maintenance organization. Annals of Epidemiology 2005, I5:7I-79.

90. Cooper GS, Virnig B, Klabunde CN, Schussler N, Freeman J, Warren JL: Use of SEER-Medicare data for measuring cancer surgery. Med Care 2002, 40(8 Suppl):IV-43-8.

91. Cooper GS, Yuan Z, Stange KC, Dennis LK, Amini SB, Rimm AA: Agreement of Medicare claims and tumor registry data for assessment of cancer-related treatment. Med Care 2000, 38(4):4|I-42|.

92. Warren JL, Harlan LC: Can cancer registry data be used to study cancer treatment? Med Care 2003, 4 I (9): 1003- 1005.

93. Baldwin LM, Adamache W, Klabunde CN, Kenward K, Dahlman C, L. WJ: Linking physician characteristics and medicare claims data: issues in data availability, quality, and measurement. Med Care 2002, 40(8 Suppl):IV-82-95.

94. Schrag D, Bach PB, Dahlman C, Warren JL: Identifying and measuring hospital characteristics using the SEER-Medicare data and other claims-based sources. Med Care 2002, 40(8 Suppl):IV-96-I03.

95. Cooper GS, Koroukian SM: Racial disparities in the use of and indications for colorectal procedures in Medicare beneficiaries. Cancer 2004, I00(2):4I8-424.

96. Freeman JL, Klabunde CN, Schussler N, Warren JL, Virnig BA, Cooper GS: Measuring breast, colorectal, and prostate cancer screening with medicare claims data. Med Care 2002, 40(8 Suppl):IV-36-42

97. Williams DR, Collins C: Racial residential segregation: a fundamental cause of racial disparities in health. Public Health Rep 2001, I I 6:404-4I6.

98. Williams DR, Rucker TD: Understanding and addressing racial disparities in health care. Health Care Financ Rev 2000, 2 I (4):75-90.

99. Meyerhardt JA, Giovannucci EL, Holmes MD, Chan AT, Chan JA, Colditz GA, Fuchs CS: Physical activity and survival after colorectal cancer diagnosis. J Clin Oncol 2006, 24(22):3527-3534.

100. Meyerhardt JA, Heseltine D, Niedzwiecki D, Hollis D, Saltz LB, Mayer RJ, Thomas J, Nelson H, Whittom R, Hantel A, Schilsky RL, Fuchs CS: Impact of physical activity on cancer recurrence and survival in patients with stage III colon cancer: findings from CALGB 89803. J Clin Oncol 2006, 24(22):3535-354I.

101. Porojnicu A, Robsahm TE, Berg JP, Moan J: Season of diagnosis is a predictor of cancer survival. Sun-induced vitamin $D$ may be involved: a possible role of sun-induced Vitamin D. J Steroid Biochem Mol Biol 2007, 103(3-5):675-678.

102. Robsahm TE, Tretli S, Dahlback A, Moan J: Vitamin D3 from sunlight may improve the prognosis of breast-, colon- and prostate cancer (Norway). Cancer Causes Control 2004, I 5(2): I 49- I 58.

103. Grant WB: Lower vitamin-D production from solar ultraviolet-B irradiance may explain some differences in cancer survival rates. I Natl Med Assoc 2006, 98(3):357-364.

104. Glaser SL, Clarke CA, Gomez SL, O'Malley CD, Purdie DM, West DW: Cancer surveillance research: a vital subdiscipline of cancer epidemiology . Cancer Causes and Control 2005, 16:1009-1019.

\section{Pre-publication history}

The pre-publication history for this paper can be accessed here:

\section{http://www.biomedcentral.com/1471-2407/7/193/pre} pub 